\title{
Flight Test of the F/A-18 Active Aeroelastic Wing Airplane
}

\author{
Robert Clarke, ${ }^{*}$ Michael J. Allen, ${ }^{\dagger}$ and Ryan P. Dibley \\ NASA Dryden Flight Research Center, Edwards, California 93523 \\ Joseph Gera ${ }^{\S}$ \\ Analytical Services \& Material, Inc., Edwards, California 93523 \\ and \\ John Hodgkinson \\ Spiral Technology, Inc., Edwards, California 93523
}

\begin{abstract}
Successful flight-testing of the Active Aeroelastic Wing airplane was completed in March 2005. This program, which started in 1996, was a joint activity sponsored by NASA, Air Force Research Laboratory, and industry contractors. The test program contained two flight test phases conducted in early 2003 and early 2005. During the first phase of flight test, aerodynamic models and load models of the wing control surfaces and wing structure were developed. Design teams built new research control laws for the Active Aeroelastic Wing airplane using these flight-validated models; and throughout the final phase of flight test, these new control laws were demonstrated. The control laws were designed to optimize strategies for moving the wing control surfaces to maximize roll rates in the transonic and supersonic flight regimes. Control surface hinge moments and wing loads were constrained to remain within hydraulic and load limits. This paper describes briefly the flight control system architecture as well as the design approach used by Active Aeroelastic Wing project engineers to develop flight control system gains. Additionally, this paper presents flight test techniques and comparison between flight test results and predictions.
\end{abstract}

$\begin{array}{ll} & \\ \text { AAW } & =\text { Active Aeroelastic Wing } \\ \text { ACU } & =\text { asymmetry control unit } \\ \text { Ada } & =\text { high-level computer language developed for the U.S. Department of Defense } \\ \text { AFW } & =\text { aileron } \\ \text { AIL } & =\text { aeroservoelastic } \\ \text { ASE } & =\text { control surface bias } \\ \text { B } & =\text { combined RFCS armed and engaged flag } \\ \text { CARMENG } & \text { control augmentation system } \\ \text { CAS } & =\text { Control Designer's Unified Interface } \\ \text { CONDUIT } & \text { control position transducer } \\ \text { CPT } & =\text { digital display indicator } \\ \text { DDI } & =\text { Dryden Flight Research Center } \\ \text { DFRC } & \end{array}$

\footnotetext{
* Aerospace Engineer, Flight Controls and Dynamics Branch, P.O. Box 273/MS 4840D, senior member.

$\dagger$ Aerospace Engineer, Flight Controls and Dynamics Branch, P.O. Box 273/MS 4840D, member.

* Aerospace Engineer, Flight Controls and Dynamics Branch, P.O. Box 273/MS 4840D.

$\S$ Aerospace Engineer, AS\&M, P.O. Box 273/MS 4830D.

ๆ Aerospace Engineer, Spiral Technology, Inc., P.O. Box 273/MS 4830B, senior member.

Note that use of trade names or names of manufacturers in this document does not constitute an official endorsement of such products or manufacturers, either expressed or implied, by the National Aeronautics and Space Administration.
} 


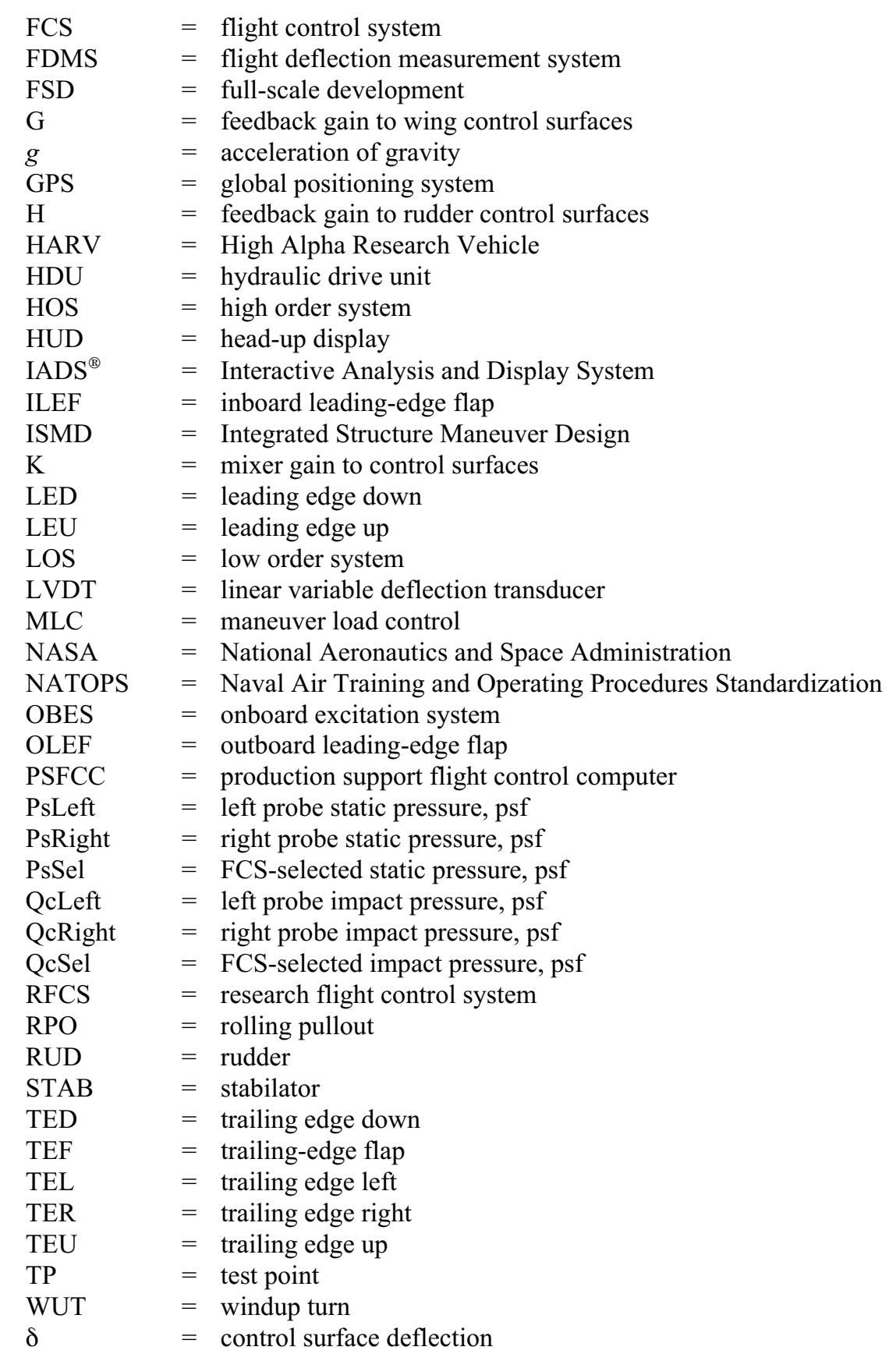

\section{Introduction}

THE Active Aeroelastic Wing (AAW) research program is a joint effort sponsored by the U.S. Air Force (USAF), NASA, and industry partners (Boeing's Phantom Works, St. Louis, Missouri; Moog Inc., Torrance, California; and BAE Systems, Binghamton, New York) demonstrating integrated control of aerodynamic and structural behavior of an airplane wing at transonic and supersonic conditions. Early design and wind-tunnel studies conducted from 1984 through 1993 demonstrated much potential for the AAW technology. ${ }^{1-4}$ These early studies usually referred to the technology as active flexible wing (AFW) rather than AAW. The earlier AFW wind-tunnel test programs included active flutter suppression, use of multiple leading- and trailing-edge wing control surfaces for roll control, and maneuver load control (MLC). For the AAW technology demonstration, ${ }^{5}$ the central objective was 
simplified to development of flight control laws designed to integrate aerodynamic and structural wing flexibility on a full-scale airplane while removing the requirement for active flutter suppression.

Early plans for the AAW program defined several requirements for the host airplane. These requirements encompassed the following essential aspects:

1) The airplane must have subsonic and supersonic capability.

2) The wing must include a minimum of two trailing-edge control surfaces and two leading-edge control surfaces.

3) The wing geometry and elastic characteristics of the airplane must exhibit trailing-edge roll control reversal.

4) The airplane must have provisions to study the effects of external stores carriage and launch.

These early requirements specified a much more ambitious program than that which was finally realized in 2005 . The AAW program deleted the external stores carriage and launch provision and effectively deleted the requirement to fly beyond trailing-edge control reversal after early flight tests showed this requirement could not be met. To keep the total program costs low, existing manned, lightweight fighters were the primary candidates for the AAW testbed airplane. Eventually the F/A-18 aircraft, with a specially modified wing, was chosen. The F/A-18 aircraft, based upon the original Northrop YF-17 design, utilized a thin and flexible wing. Flight tests in the early full-scale development (FSD) phase showed degraded roll performance in the transonic and supersonic regimes but exhibited no flutter problems. The contractor fixed the roll performance problem with two "roll-mods" to the airplane structure and flight control system (FCS). These roll modifications stiffened the wing box and changed the flight control law use of trailing-edge flaps (TEFs), ailerons, and leading-edge flaps to provide additional rolling performance. The basic F/A-18 control laws also rely heavily on differential stabilator for roll control at the transonic and supersonic flight conditions. The AAW program undid the major physical modifications to the wing of the airplane with specially built wing covers, which returned the wing to the preproduction torsional stiffness levels. Modifications were also made to separate the leading-edge flap drive system into independently controlled inboard and outboard flaps as well as increase their upward deflection limits.

Early stumbling blocks to the projected schedule also occurred as modeling requirements, driven by the safety-of-flight concerns, were developed and plans were made to address the increased scope that these safety concerns created. These concerns led to additional aerodynamic parameter estimation flight tests on the F/A-18 Systems Research Aircraft and an early flight phase on the AAW airplane to conduct aerodynamic and structural modeling tests.

This paper will illustrate how the program requirements were accomplished. Additionally, the paper will describe how the authors developed flight control laws and safely tested both these and contractor-developed control laws. The paper will also present comparisons of predicted and measured airplane response at several flight conditions. Finally, the paper will discuss several lessons learned during the development and flight test of the AAW airplane.

\section{Background on Roll Control Reversal}

Figure 1 shows roll control effectiveness as a function of dynamic pressure for a generic fighter airplane. For purposes of this paper, the differential deflection of the wing control surfaces is defined as the total angle between the left and right control surfaces (left minus right for trailing edge and right minus left for leading edge). This definition provides positive rolling moment for positive deflection of the individual control surface, at least approaching the point that reversal occurs. Roll reversal is simply the point at which roll effectiveness for a control surface switches sign. Roll control effectiveness breaks naturally into four regions divided by airplane roll control effector characteristics.

- Region I - trailing-edge control surfaces are paramount and leading-edge control surfaces are ineffective for generating rolling moment.

- Region II - trailing- and leading-edge control surfaces are equally effective.

- Region III - trailing-edge effectiveness has gone to zero and all rolling moment is generated by the leading-edge control surfaces.

- Region IV - trailing-edge roll control is reversed and leading-edge control surfaces continue to generate even larger rolling moments. 


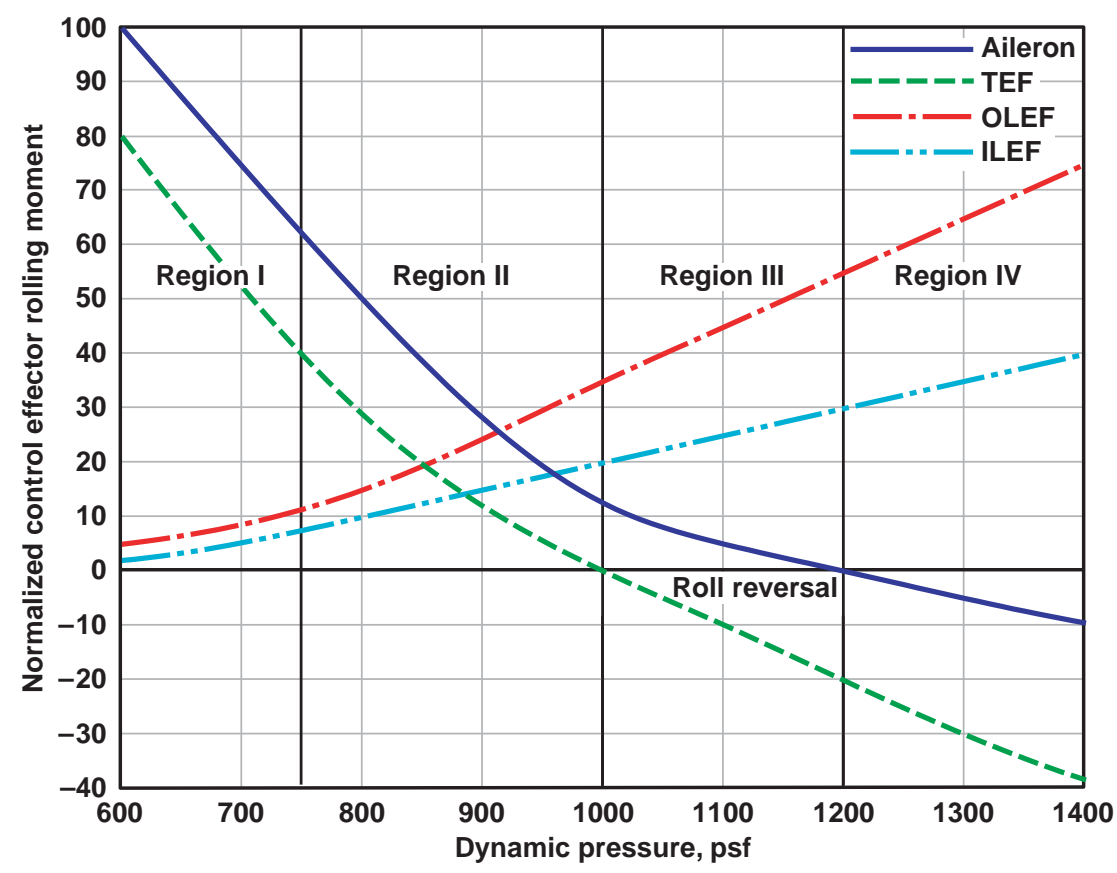

Figure 1. Typical roll control effectiveness as function of dynamic pressure.

In the simplest analytic model, leading- and trailing-edge control surfaces generate rolling moments by changing the effective airfoil camber of the wing. At high dynamic pressure, the control deflections and torsional flexibility of the wing complicate this simple concept by changing the local angle of attack across the wingspan as it rotates in relation to its elastic axis. For trailing-edge control surfaces, the changes in airfoil camber tend to dominate at low dynamic pressure; but as dynamic pressure increases, their roll control effectiveness tends to be reduced because of reduction in local angle of attack. The limit condition for this effect is referred to as aileron reversal and has typically forced the control designer to consider alternate means to provide roll control in this part of the flight envelope. Reduction in wing torsional stiffness causes a reduction in the dynamic pressure at which trailing-edge control surfaces start to exhibit reversal. Conversely, for leading-edge control surfaces, the camber effect is small and the local angle-of-attack change tends to dominate. Leading-edge control surfaces do not exhibit a reversal tendency; but as wing torsional stiffness is reduced, the leading-edge control surface roll effectiveness is proportionally increased.

\section{Airplane Description}

This section describes the research airplane configuration. The discussion also includes an overview of the flight control and instrumentation systems.

\section{A. Airplane Configuration}

Figure 2 shows the AAW airplane, which is a modified single-seat F/A-18 aircraft. The airplane was built from parts of two aircraft - the Navy provided the airframe with tail number 853, and NASA procured wings from an early prototype airplane with tail number 840 . The airplane has been specially modified with extensive loads instrumentation added to both right and left wing structure, a flight deflection measurement system (FDMS), a research noseboom, and a research flight control system (RFCS). 


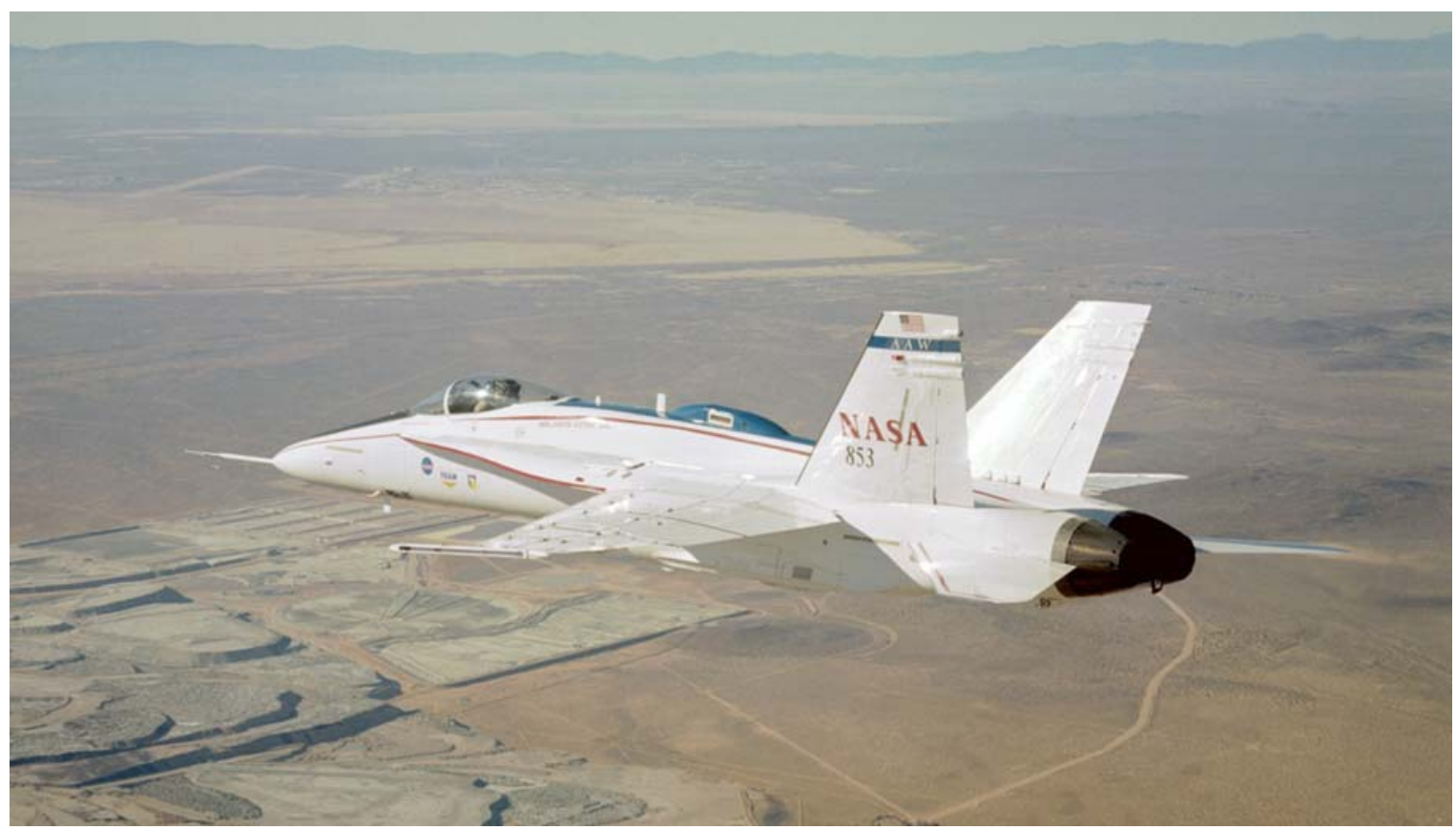

Figure 2. Active aeroelastic wing F/A-18 airplane begins Phase II flight test program.

Boeing's Phantom Works, St. Louis, Missouri, performed modifications to the leading-edge flap drive system and returned the wing back to essentially the preproduction state. The modifications to the leading-edge flap drive system entailed splitting the inboard and outboard drive systems. The existing hydraulic drive unit (HDU) rotary actuator was retained to drive the inboard flap section and an additional power drive unit rotary actuator was added in each wing leading edge to drive the outboard flap. Table 1 shows the actuator and control surface characteristics of the AAW airplane, including the modified leading-edge flaps. This table also shows structural limits for the wing control surfaces. Because of F/A-18 fleet experience with leading-edge flap failures resulting in loss of control, an asymmetry control unit (ACU) or auxiliary brake was incorporated into each leading-edge flap drive system. A slip feature was added to each ACU to ensure that catastrophic shaft failure would not result from locking the brake. Each ACU would lock its associated leading-edge flap if either a mismatch of commanded and actual position exceeded a fixed tolerance or if overspeed (runaway) conditions were met.

Table 1. Active aeroelastic wing actuator and control surface characteristics.

\begin{tabular}{|c|c|c|c|c|c|}
\hline Surface & $\begin{array}{l}\text { Position } \\
\text { limit, deg }\end{array}$ & $\begin{array}{l}\text { Rate limit, } \\
\text { deg/sec }\end{array}$ & $\begin{array}{l}\text { Actuator force or } \\
\text { moment capability }\end{array}$ & $\begin{array}{l}\text { Maximum } \\
\text { horn arm, in. }\end{array}$ & Structural limit, in-lb \\
\hline Stabilator & $\begin{array}{r}10.5 \text { (TED) } \\
24 \text { (TEU) }\end{array}$ & 40 & $\begin{array}{l}29,940 \mathrm{lb} \text { (extend) } \\
27,540 \mathrm{lb} \text { (retract) }\end{array}$ & 12.0 & $\mathrm{X}^{*}$ \\
\hline Rudder & $\begin{array}{l}30 \text { (TEL) } \\
30 \text { (TER) }\end{array}$ & 56 & $\begin{array}{l}15,730 \mathrm{lb} \text { (extend) } \\
13,880 \mathrm{lb} \text { (retract) }\end{array}$ & 1.43 & $\mathrm{X}^{*}$ \\
\hline TEF & $\begin{array}{r}45 \text { (TED) } \\
8 \text { (TEU) }\end{array}$ & 18 & $\begin{array}{l}18,060 \mathrm{lb} \text { (extend) } \\
14,330 \mathrm{lb} \text { (retract) }\end{array}$ & 9.08 & $\begin{array}{l}+157,000 \\
-210,000\end{array}$ \\
\hline Aileron & $\begin{array}{l}45 \text { (TED) } \\
25 \text { (TEU) }\end{array}$ & 100 & $\begin{array}{l}13,100 \mathrm{lb} \text { (extend) } \\
12,090 \mathrm{lb} \text { (retract) }\end{array}$ & 4.0 & $\begin{array}{l}+50,000 \\
-52,000\end{array}$ \\
\hline ILEF & $\begin{array}{r}34 \text { (LED) } \\
5 \text { (LEU) }\end{array}$ & 15 & $\begin{array}{c}+/-333,000 \text { in-lb } \\
\text { (minimum breakout load) }\end{array}$ & Rotary & $\begin{array}{l}+427,000 \\
-240,000\end{array}$ \\
\hline OLEF & $\begin{array}{l}34 \text { (LED) } \\
10 \text { (LEU) }\end{array}$ & 45 & $\begin{array}{c}+/-81,560 \text { in-lb } \\
\text { (minimum breakout load) }\end{array}$ & Rotary & $\begin{array}{r}+119,000 \\
-90,000\end{array}$ \\
\hline
\end{tabular}

* $\mathrm{X}=$ not monitored. 


\section{B. Flight Control System}

Building upon the efforts of the High Alpha Research Vehicle (HARV) ${ }^{6}$ and the F/A-18 Production Support Flight Control Computer (PSFCC) ${ }^{7}$ programs, the AAW project elected to use a RFCS. The basic FCS of the F/A-18 airplane is a quad-redundant GE 701E computer set. The RFCS used is an upgraded PSFCC system with a 68040 processor replacing the PACE 1750 unit. Additional output commands were added to drive the inboard and outboard leading-edge flaps independently.

Figure 3 shows the FCS elements. In this figure, the number of staggered boxes illustrates the redundancy level of each component and a dashed line surrounds the RFCS component. As in both the HARV and PSFCC programs, the sensor redundancy management and actuator signal management are performed in the 701E. Communication between the 701E and RFCS processors is accomplished through dual-port random access memory. The control laws contained in the RFCS were written in Ada with most of the routines auto-coded by the contractor from Matrix-X block diagrams. The RFCS control laws were run at 80 samples per second for the pitch and roll axes, whereas the yaw axis was run at 40 samples per second, which followed the standard 701E computation rates. Transition between the 701E and RFCS control was always under pilot control. Likewise, transition between RFCS and $701 \mathrm{E}$ was either under pilot control or a result of automatic disengage logic. Integrator pre-seed logic and transient free switches in the actuator commands were added to the RFCS implementation to ensure that engage/disengage transients would be minimal. Data from the RFCS, including commands and internal control system variables, were available in several modified MIL-STD 1553 bus messages.

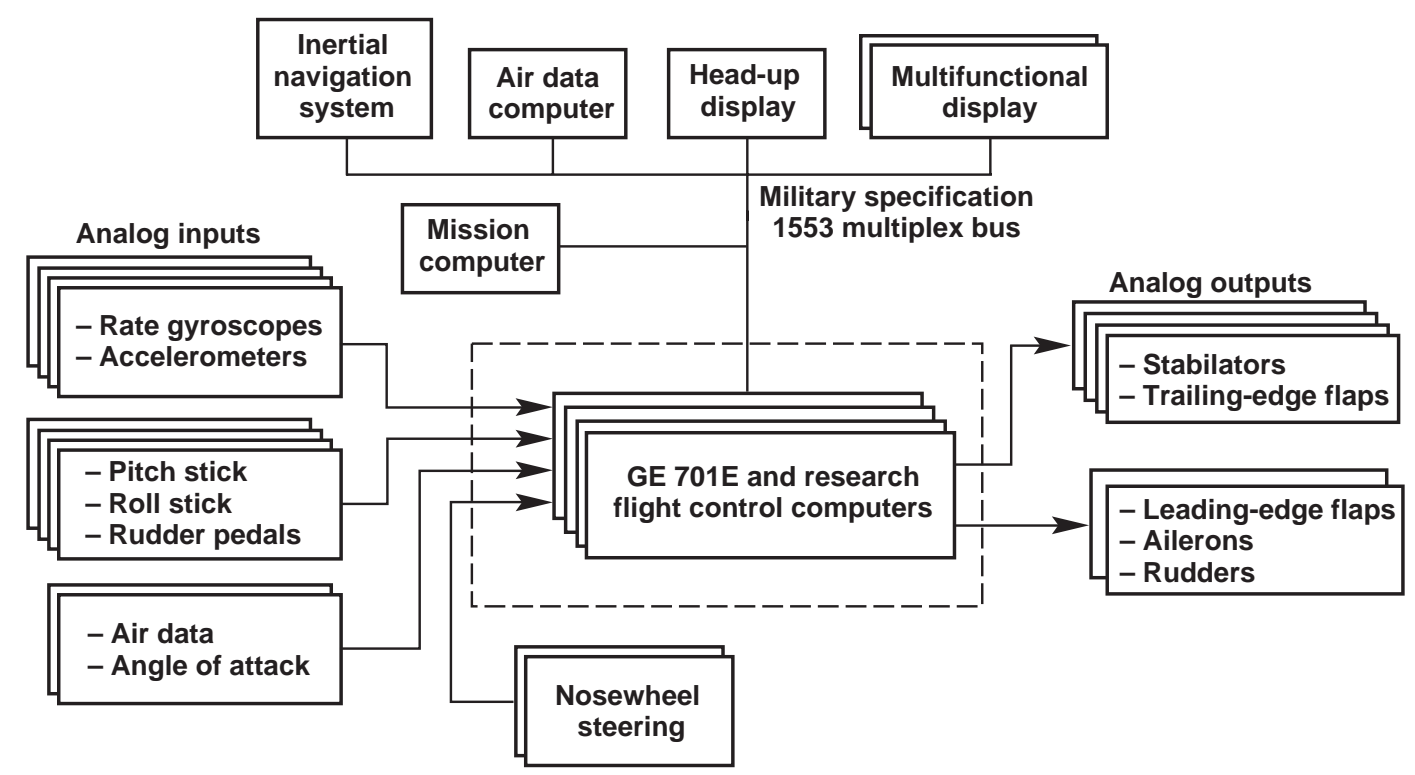

Figure 3. F/A-18 control system components.

In past programs, the use of the RFCS had an additional advantage - the control laws were designated non-safety-of-flight and system testing would be conducted at a reduced level. The flight envelope, by nature of the high dynamic pressures required to twist the wing structure, precluded this safe harbor for the AAW flight program. FCS developers could not make the assumption that either pilot action or automatic downmode could return the F/A-18 airplane back to its safe envelope in the event of sudden loss of control caused by the RFCS. Therefore, the AAW RFCS software, which was designated safety-of-flight, was developed and proven to this higher standard. The use of the RFCS, however, allowed the project to use the standard 701E for routine tasks (i.e., take-off, landing, and maneuvering from one test point (TP) to another).

During the two phases of the flight program, the RFCS was used in different modes. In Phase I, the RFCS provided independent excitation of the various aerodynamic control surfaces superimposed on the conventional F/A-18 control surface commands. In Phase II, the RFCS provided inner-loop control, executing the newly developed AAW control laws. ${ }^{8}$ The pilot interface that activated the RFCS control system mode used a two-step process. First, the pilot would lift the guarded arm/disarm switch located between the digital display 
indicators (DDIs). Second, the pilot would press the nosewheel steering button, located on the control stick, to engage the RFCS. A paddle switch, also located on the control stick, provided a backup method of disengagement from RFCS. In Phase II, a RFCS disengage tone was added to the airplane to provide aural feedback to the pilot of RFCS disengagement.

\section{Instrumentation System}

Before any of the flight tests were conducted, a wing loads instrumentation system (comprised of approximately 200 strain-gage bridges) was installed and extensive calibration was conducted. ${ }^{9}$ This calibration included wing-root and wing-fold shear, torsion, and bending loads plus all wing control surface actuator hinge moments. Redundant wing load equations were calibrated using single-point, multipoint, and distributed loads. The development of multiple load equations allowed for backup equations should one or more strain gages develop problems after flight tests were underway. The FDMS system, which provided low frequency (12.5 samples per second) 16-point wing shape, was calibrated by comparison with ground test string potentiometers.

The flight test noseboom was added to provide high quality air data. The basic 701E FCS uses dual uncalibrated static and impact pressures for FCS gain scheduling. This system has large errors in both altitude and Mach number at low speed supersonic conditions. These air data errors prevented this system from being used in aerodynamic and loads modeling. In preparation for the Phase I research efforts, air data calibration maneuvers (e.g., level acceleration runs, push-over pull-ups, and wind circles) were added to the flight test plan.

Additional aircraft instrumentation included a high quality inertial navigation system, differential global positioning system (GPS) unit, linear and vibration accelerometers, rate gyroscopes, and control surface position measurements. The system also included basic engine performance sensors, aircraft fuel weight, and MIL-STD-1553 monitoring for FCS parameters. As part of the instrumentation upgrades for Phase II, rudder hinge moments were also instrumented; and one row of upper and lower surface pressures was added to each wing panel at approximately the mid-aileron location.

\section{Phase I Flight Test}

Uncertainty about the fidelity of the aerodynamic and loads models at the program design reviews influenced a desire to confirm these models in what developed into the Phase I effort. This phase of flight test was conducted from November 2002 to June 2003 and comprised 51 total flights. These flight tests had three primary objectives: 1) prove that the modified F/A-18 airplane envelope was flutter free, 2) demonstrate the low-speed flight characteristics of the worst-case outboard leading-edge flap (OLEF) failure, and 3) gather data to use in development of flight-derived aerodynamic and loads model updates based upon an onboard excitation system (OBES). The aerodynamic and loads models derived in this phase were then used in designing the control laws that were to be flown in Phase II.

For Phase I the OBES, which was just a special version of the RFCS software, was used to provide independent excitation to each of the control surfaces. When the OBES was not actively moving a control surface, the RFCS would otherwise just "pass-through" the basic 701E control system commands. The pass-through control laws had a restricted envelope for each OBES maneuver, limiting pitch rate, normal acceleration, roll rate, yaw rate, and lateral acceleration to levels that would prevent accidental harm to the AAW structure. Figure 4 shows the flight test envelope. No OBES maneuvers could be flown at two of the supersonic test points as these test points proved to be outside of the performance envelope of the AAW airplane. The figure shows that these test points were already expected to be outside of the level flight performance of the AAW airplane, but the hope was that shallow dive angles could allow testing at their conditions. External FDMS targets, external wiring, wing surface pressure instrumentation, and the camera pods may have contributed to additional drag at these conditions. Table 2 shows the nominal (based upon F/A-18 standard air data measurements) and true conditions (based upon the calibrated noseboom measurements) that were flown for each of the test points. As previously mentioned, testing was not accomplished at TPs 18 and 20. The table indicates this inability with X's in the true conditions columns for these test points. The table also shows that errors in the true Mach number at supersonic conditions were larger than expected. Altitude errors of several thousand feet were seen as the pilot accelerated to the Mach 1.1 indicated condition. For this reason, while the pilot flew indicated Mach number, the pilot used an onboard GPS altitude indicator to keep from chasing apparent changes in altitude displayed on the head-up display (HUD). 


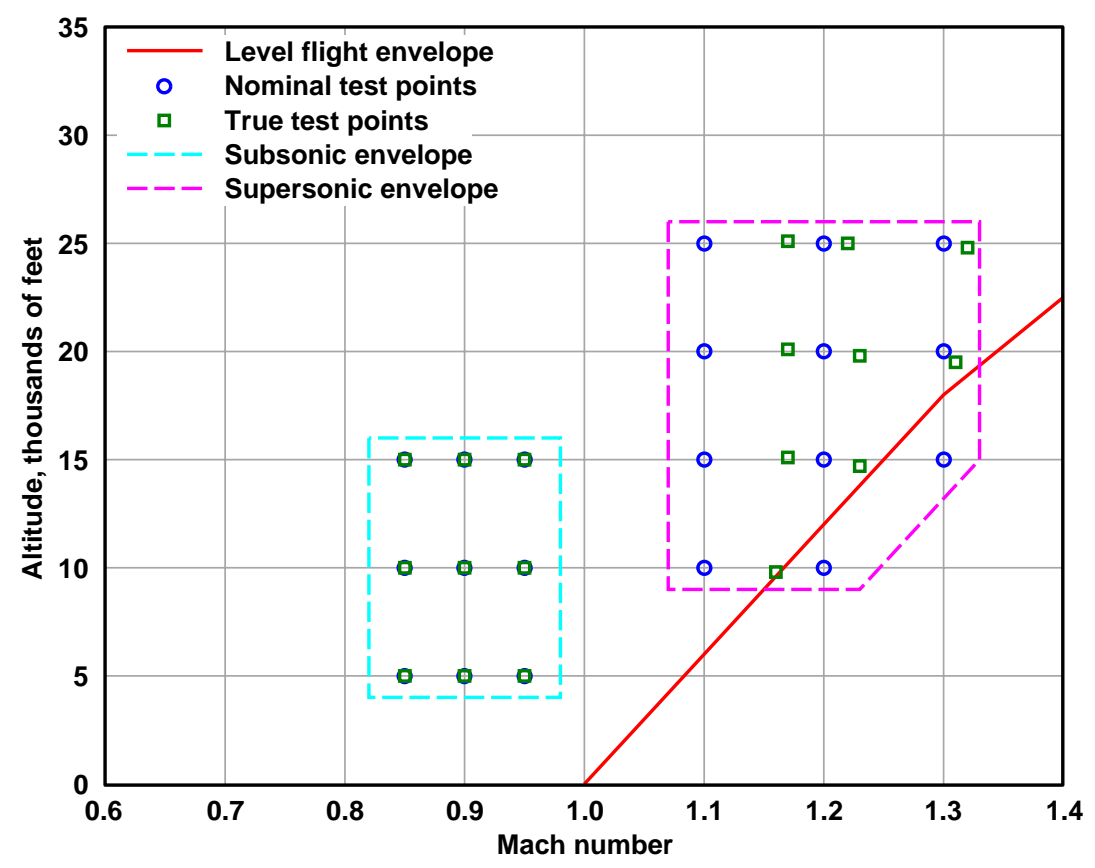

Figure 4. Active aeroelastic wing flight test envelope.

Table 2. Active aeroelastic wing nominal and true flight conditions.

\begin{tabular}{ccccc}
\hline $\begin{array}{c}\text { Flight } \\
\text { condition }\end{array}$ & $\begin{array}{c}\text { Nominal } \\
\text { Mach no. }\end{array}$ & $\begin{array}{c}\text { Nominal altitude, } \\
\mathrm{ft}\end{array}$ & $\begin{array}{c}\text { True } \\
\text { Mach no. }\end{array}$ & $\begin{array}{c}\text { True altitude, } \\
\mathrm{ft}\end{array}$ \\
\hline 1 & 0.85 & 15,000 & 0.85 & 15,000 \\
2 & 0.90 & 15,000 & 0.90 & 15,000 \\
3 & 0.95 & 15,000 & 0.95 & 15,000 \\
4 & 0.85 & 10,000 & 0.85 & 10,000 \\
5 & 0.90 & 10,000 & 0.90 & 10,000 \\
6 & 0.95 & 10,000 & 0.95 & 10,000 \\
7 & 0.85 & 5,000 & 0.85 & 5,000 \\
8 & 0.90 & 5,000 & 0.90 & 5,000 \\
9 & 0.95 & 5,000 & 0.95 & 5,000 \\
10 & 1.10 & 25,000 & 1.17 & 25,100 \\
11 & 1.20 & 25,000 & 1.22 & 25,000 \\
12 & 1.30 & 25,000 & 1.32 & 24,800 \\
13 & 1.10 & 20,000 & 1.17 & 20,100 \\
14 & 1.20 & 20,000 & 1.23 & 19,800 \\
15 & 1.30 & 20,000 & 1.31 & 19,500 \\
16 & 1.10 & 15,000 & 1.17 & 15,100 \\
17 & 1.20 & 15,000 & 1.23 & 14,700 \\
18 & 1.30 & 15,000 & $\mathrm{X}^{*}$ & $\mathrm{X}^{*}$ \\
19 & 1.10 & 10,000 & 1.16 & 9,800 \\
20 & 1.20 & 10,000 & $\mathrm{X}^{*}$ & $\mathrm{X}^{*}$ \\
\hline \hline
\end{tabular}

$* \mathrm{X}=$ test points not flown. 
The following maneuvers were flown at each of the test conditions: 1) aeroservoelastic (ASE) OBES maneuvers used to clear the flutter envelope, 2) aerodynamic and loads modeling OBES doublets, 3) 5-g windup turns (WUT), 4) bank-to-bank and $360^{\circ}$ rolls at up to full lateral stick, and 5) 4-g rolling pullout (RPO). The modeling efforts used not only the OBES doublet maneuvers, but also used the WUT, bank-to-bank and $360^{\circ}$ rolls, and RPOs demonstration maneuvers. These large amplitude maneuvers helped to confirm the modeling results produced by matching the small amplitude doublets. A good model must be able to match both parameter estimation type responses (like the OBES doublets) and the large demonstration maneuvers, otherwise assumptions about either superposition or linearity break down. References 10 and 11, respectively, provide descriptions of the aerodynamic and loads model development efforts from Phase I data.

During Phase I flight test, the noseboom air data system was calibrated using standard NASA Dryden Flight Research Center (DFRC, Edwards, California) techniques. After the true air data was available, comparison of the production air data system with the calibrated noseboom data allowed a simple FCS air data model to be designed for simulation use. Before this modeling effort, the DFRC simulation presented true air data to the flight control and mission computers. The computed inverse air data model ensured that the flight computers, used in simulation, accurately reflected the flight data. The model took true aircraft state and computed the inverse calibration of impact and static pressure for both left and right aircraft air data probes. Verification and validation testing of the FCS for Phase II required this level of fidelity to ensure that the flight software would be tested at the true conditions, whereas the computers referenced impact and static pressures necessary to set the correct flight condition and other gain schedules.

The OBES required the pilot to: 1) arm and engage the RFCS, 2) key the OBES index into the DDI system, and 3) activate the OBES maneuver. Thirty-one OBES maneuvers were designed to meet the three Phase I objectives. This paper will not discuss the OBES maneuvers used for flutter envelope clearance; however, the following paragraphs will discuss those designed for the other two objectives.

Table 3 lists the three OBES maneuvers designed to test a simulated failed OLEF. These three maneuvers were designed to simulate a failed OLEF that is failed at a leading-edge up position. The worst-case scenario envisioned was the left OLEF failed up $10^{\circ}$. The results of flight test showed no adverse tendency with this simulated failure until full flaps were engaged and angle of attack was increased above $10^{\circ}$. With all of those conditions met, the airplane experienced moderate wing drop of the left wing (the wing with the simulated failed OLEF). Flight operating limits and pilot emergency procedures were modified because of the characteristics found during Phase I flight tests.

\begin{tabular}{|c|c|}
\hline OBES index & Left OLEF command, deg \\
\hline 21 & -3 \\
\hline 22 & -6 \\
\hline 23 & -10 \\
\hline
\end{tabular}

Table 4 lists the collective OBES doublet maneuvers and Fig. 5 shows an example of the largest collective doublet flown at one of the test points. The figure shows the response of the flight control surfaces with active feedbacks. Because of these FCS feedbacks, the pure OBES doublet has been changed into what is shown in the figure. The figure also illustrates how each of the control surfaces responded to the other control surface doublets. Likewise, Table 5 lists the differential OBES doublet maneuvers. Similarly, Fig. 6 represents an example of the largest differential doublet maneuvers. These doublet maneuvers were used to identify individual control surface effectiveness for the AAW aerodynamic and loads model databases. After the OBES was activated, the software waits for 5 seconds and then starts the sequence of automatic doublet deflections defined in the figures. The doublet deflections were added to the $701 \mathrm{E}$ control surface commands before being sent to the individual actuators. When the largest differential doublets are compared with the control surface deflection limits, an obvious inference is that the leading-edge flap was not exercised over a large range when compared to its maximum displacement. Primarily this use of small doublets was because of concerns with exceeding hinge-moment limits and damaging aircraft structure, but was also partly a result of the belief that only small deflections of the control surfaces would be required to roll the airplane at these flight conditions. ${ }^{5}$ 
Table 4. Amplitudes of the collective onboard excitation system doublet maneuvers.*

\begin{tabular}{ccccccc}
\hline \hline OBES index & $\delta_{\text {OLEF }}$ & $\delta_{\text {ILEF }}$ & $\delta_{\text {TEF }}$ & $\delta_{\text {OLEF }}$ and $\delta_{\text {ILEF }}$ & $\delta_{\text {AIL }}$ & $\delta_{\text {STAB }}$ \\
\hline 24 & 3 & 3 & 5 & 3 & 6 & 0.8 \\
25 & 2 & 2 & 4 & 2 & 5 & 0.8 \\
26 & 1 & 1 & 3 & 1 & 4 & 0.8 \\
\hline \hline
\end{tabular}

* Numerical values of $\delta$ are represented in degrees.

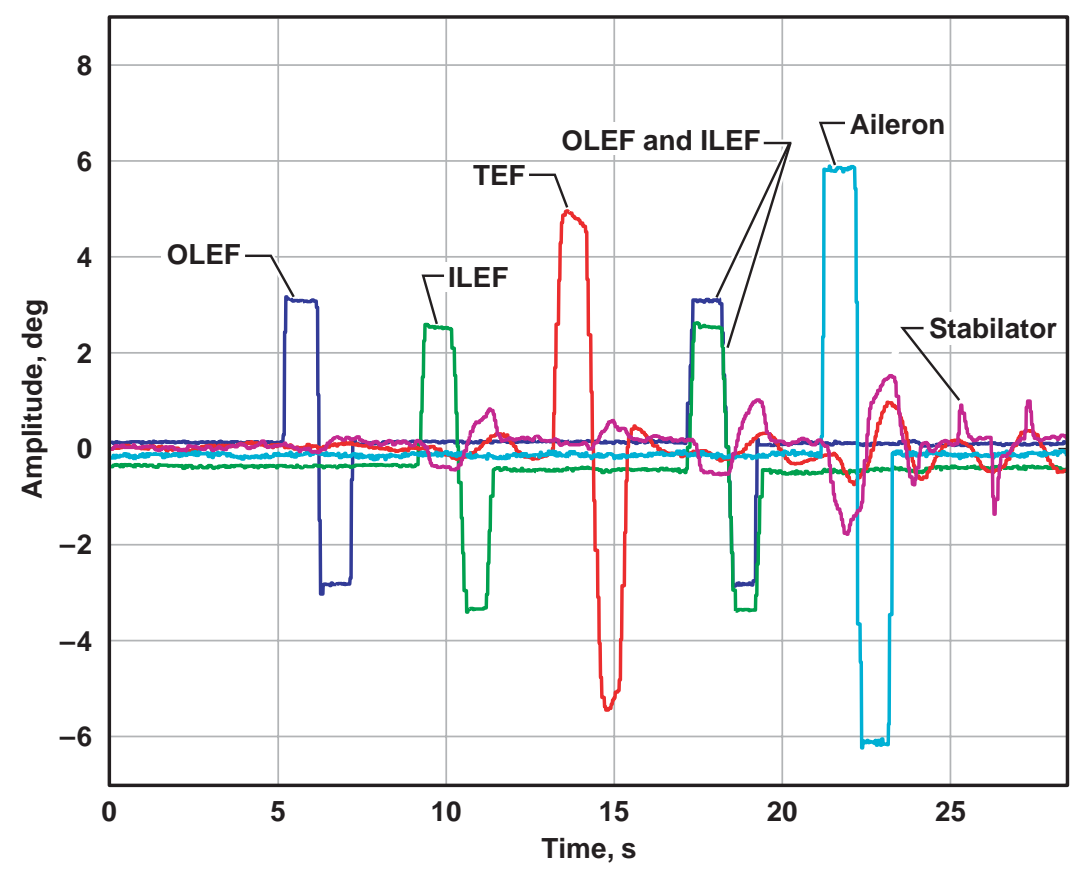

Figure 5. Collective onboard excitation system doublet maneuvers. 
Table 5. Amplitudes of the differential onboard excitation system doublet maneuvers.*

\begin{tabular}{cccccccc}
\hline \hline OBES index & $\delta_{\text {RUD }}$ & $\delta_{\text {OLEF }}$ & $\delta_{\text {ILEF }}$ & $\delta_{\text {TEF }}$ & $\delta_{\text {AIL }}$ & $\delta_{\text {STAB }}$ & $\delta_{\text {OLEF }}$ and $\delta_{\text {ILEF }}$ \\
\hline 27 & 4 & 6 & 6 & 10 & 12 & 6 & 6 \\
28 & 4 & 4 & 4 & 8 & 10 & 6 & 4 \\
29 & 4 & 2 & 2 & 6 & 8 & 6 & 2 \\
\hline \hline
\end{tabular}

* Numerical values of $\delta$ are represented in degrees.

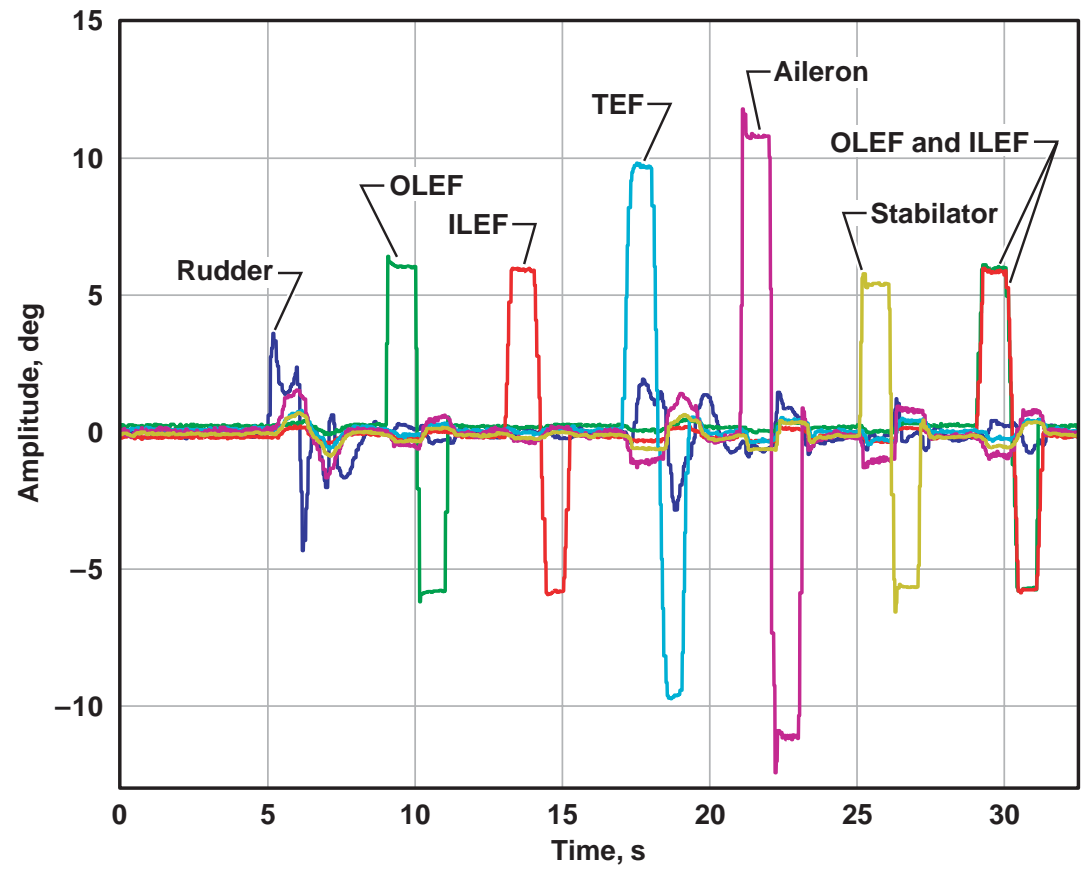

Figure 6. Differential onboard excitation system doublet maneuvers.

Four surprises occurred during Phase I flight test. First, aileron hinge-moment loads frequently prevented the project team from testing full lateral stick inputs during 701E $1-g$ and elevated $g$ roll maneuvers. These 701E roll maneuvers were designed to provide the baseline for comparison of the Phase II roll performance. The aileron hinge-moment problem became a significant driver for the Phase II FCS design. The second surprise was that no aileron reversal was found during any of the OBES maneuvers. Only the onset of reversal was found, where rolling moment as a result of aileron was essentially zero. The third surprise was that the aileron itself experienced severe structural deformation across its span. As a partial explanation, it should be noted that the aileron actuator is located at the far inboard location of the aileron control surface and a free hinge is located at the far outboard location. At many of the highest dynamic pressures, the inboard control position transducer (CPT) and linear variable deflection transducer (LVDT) showed that the aileron responded to the downward command; but the outboard CPT, located at the free hinge, showed the aileron deflecting upward. Sometimes this upward deflection was as large as the downward command. The final surprise was that the new control law designs required much larger deflections of the wing control surfaces to achieve adequate roll performance. In hindsight, the OBES maneuvers should have exercised the leading-edge control surfaces over larger ranges to reduce the extrapolation used in the development of the aerodynamic and loads models. At many of the test points, the largest OBES maneuvers flown were the medium doublets, which meant that as much as five times larger motion of the OLEF was used in the Phase II research control laws. 


\section{Phase II Flight Test}

To keep the cost of control law design and test low, the program decided to treat each of the test points as a separate design point. Rather than requiring development of a full envelope control law, the problem was reduced to 18-point designs. Each test point, therefore, had its own static and impact pressure envelope built using air data information developed from the Phase I flight tests. The control laws were then designed using the true conditions that represented the center of all of the OBES doublets performed at that condition. The arming of the RFCS was limited to a small envelope around this true condition. Simple logic required that these arming envelopes were distinct. The disengage envelopes were determined by encompassing all of the demonstration maneuvers performed at each test condition using the 701E. The logic behind this determination was that the Phase II RFCS would need the same envelope as the Phase I demonstration maneuvers required. In this way, the limits on the disengage envelopes automatically compensated for the difficulty of maintaining airspeed and altitude at the supersonic test points. The disengage envelopes were not required to be distinct; in fact, the disengage envelopes were allowed to have overlap with nearby test envelopes because the gains would be locked after the system was armed and engaged.

To aid the pilot in achieving the correct airspeed and altitude envelope for each of the test points, a real-time display was developed for flight monitoring. Figure 7 shows a portion of this display, which was developed using the Interactive Analysis and Display System (IADS ${ }^{\circledR}$ ). The display shows the RFCS status in the upper left corner and labeled static and impact pressure envelopes for each of the 18 test points. Blue rectangles inside of the shaded disengage boundaries represent the arming envelopes. The black dot at TP 13 represents indicated static and impact pressure conditions of the airplane. In this portion of the display, static pressure is represented on the vertical axis (low altitude at the bottom and high altitude on the top) and impact pressure on the horizontal axis (slow speed to the left and high speed to the right). Switches were provided to allow the display to engage a "moving map" mode, additional envelope information, FCS air data logic, and flight controller's "director" information. The far right side of the display has a stripchart indicating a time history of the RFCS arm/engage status. If the RFCS disengaged, the display could be scrolled backwards in time to allow the user to ascertain if disengagement was the result of violating the air data envelope limits. Underneath the arm/engage stripchart, digital output of the FCS selected, left and right probe static, and impact pressures is presented. This display allowed the test conductor to have excellent situational awareness and aided him in making terminate maneuver calls to the pilot if the test conductor saw the airplane approaching a test point envelope boundary. The terminate calls helped keep the pilot from having excessive lateral stick inputs after the RFCS disengaged (where these lateral stick inputs would have caused aileron hinge-moment overload). As previously mentioned, an aural RFCS disengage tone was also added to the airplane to help the pilot be aware of uncommanded RFCS disengagement.

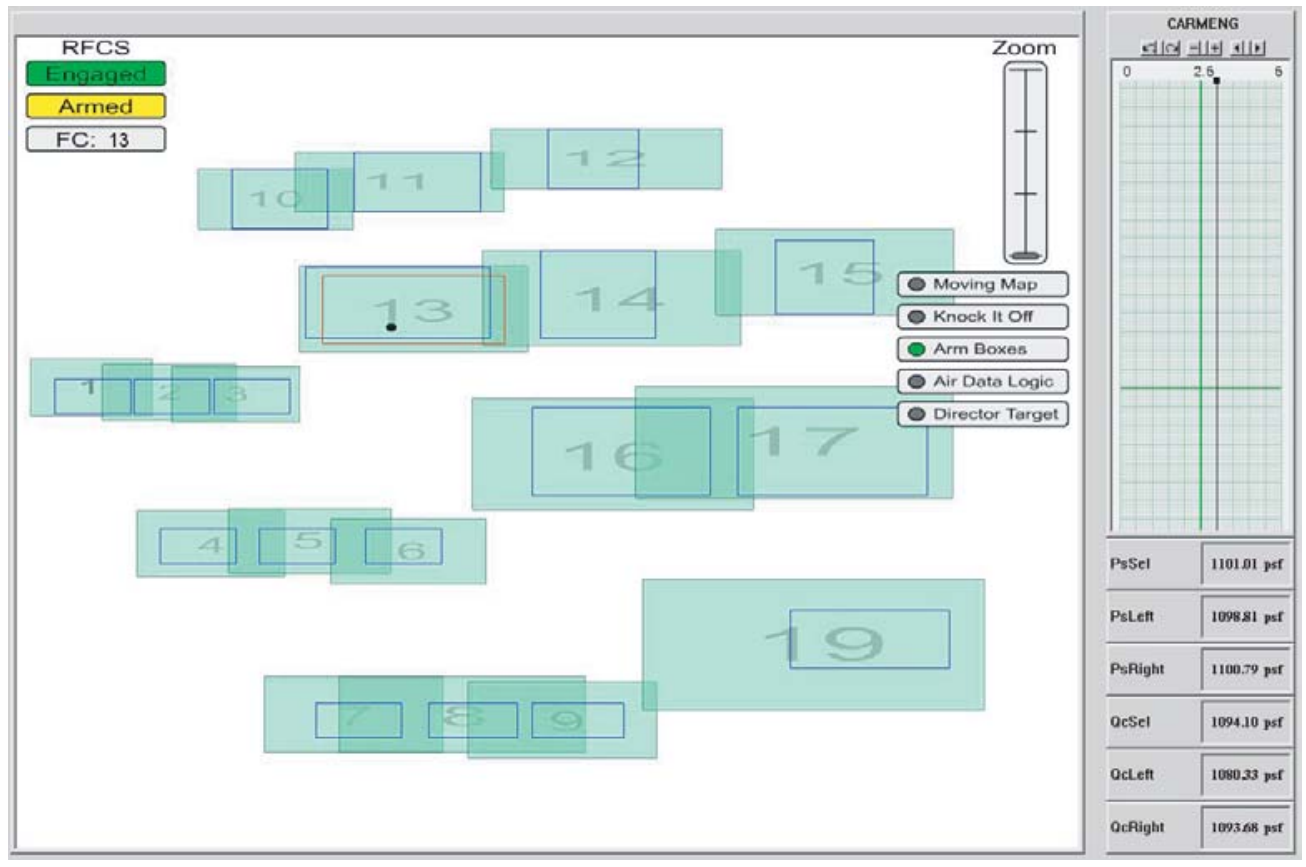

Figure 7. Real-time display of active aeroelastic wing envelopes and research flight control system status. 
Both NASA and Boeing engineering teams developed a set of requirements and control laws for the AAW airplane. This apparent duplication of effort provided additional design options to the project and ensured that the test team would understand the complexities of the AAW control law design process. The Boeing engineers used a design process called Integrated Structure Maneuver Design ${ }^{12}$ (ISMD), while the NASA engineering team used the Control Designer's Unified Interface $\left(\right.$ CONDUIT $\left.^{\circledR}\right)$ design tool. These two different approaches each solved a slightly different, but related optimization problem. CONDUIT $^{\circledR}$ maximized airplane roll rate while simultaneously satisfying the rest of the requirements as explicit constraints. ISMD optimized the dual problem of minimizing loads while meeting a roll performance constraint, necessitating a postdesign analysis of the other requirements and possibly leading to additional redesign efforts. These two optimization approaches were described in early AFW work, ${ }^{13}$ and each approach has both strengths and weaknesses.

The criteria regarding airplane performance, stability, flying qualities, structural limits, and control surface hinge moments were collected in a project control law requirements document. These criteria were drawn from existing MIL Handbook 1797 and recent Boeing, USAF, and NASA experience, as well as other relevant documentation. The document presented goals (designated level 1) and requirements (designated level 2) that were used to ensure proposed control law designs met a minimum "safe-to-fly" level. The flight program did not emphasize piloting tasks to explore handling characteristics. Therefore, the criteria from the requirements document, evaluated for WUTs and maximum performance roll maneuvers, constituted a check that the handling characteristics would not restrict the use of AAW technology.

This second phase of flight test was conducted from December 2004 to March 2005 and comprised 35 total flights. During the flight-testing, the following RFCS maneuvers were performed at each test point:

1) RFCS engage and immediate disengage to check for transients,

2) Stick raps and pilot doublets to look for control system stability and to allow the pilot to feel the airplane out,

3) 5-g WUT to see the pitch characteristics and wing loads at elevated $g$,

4) Bank-to-bank or $360^{\circ}$ rolls at 25-, 50-, 75-, and 100-percent lateral stick, and

5) 4-g RPO at 25-, 50-, 75-, and 100-percent lateral stick.

Initial buildup was left rolls, and right rolls generally followed. RPOs were only performed with a left entry and right roll. Some back-to-back RFCS and 701E WUTs were performed to examine the MLC performance. The slow buildup in lateral stick was the result of concerns about overloading structure with the new control laws. Even with all of the attention that the aileron received during design efforts, the aileron hinge moment dominated the concerns during Phase II flight test.

\section{A. Longitudinal Axis}

In the longitudinal axis, the RFCS was either designed to replicate the 701E control system or to provide a level of MLC. Figure 8 presents a simplified pitch-axis block diagram. The following paragraphs discuss flight test data, representative of that obtained with the pitch-axis MLC design. In order to compare the RFCS performance to that of the baseline 701E, 5-g WUTs were performed back-to-back with the RFCS and 701E at most of the 18 test points. Performing the maneuvers back-to-back removed the requirement to compensate for weight and center of gravity differences. The data presented in this pitch-axis section were obtained at a subsonic region II test point. Figure 9 depicts strain-gage measurements of the wing-root and fold-line bending and torsion on the left and right wing during the WUTs with the limit load envelope for each component. Attention was focused on the four components of the ISMD objective function, namely wing-root and fold-line bending and torsional moments. As observed from the comparison of the RFCS and the 701E data, the peak loads remained well within the loads envelope for both sets of control laws. Significant differences between the two control laws can be noted only in the wing-root torsional moments. With the 701E, the torsion became more negative with increasing normal load factor; whereas with the RFCS, the torsion moment remained approximately constant at positive values. 


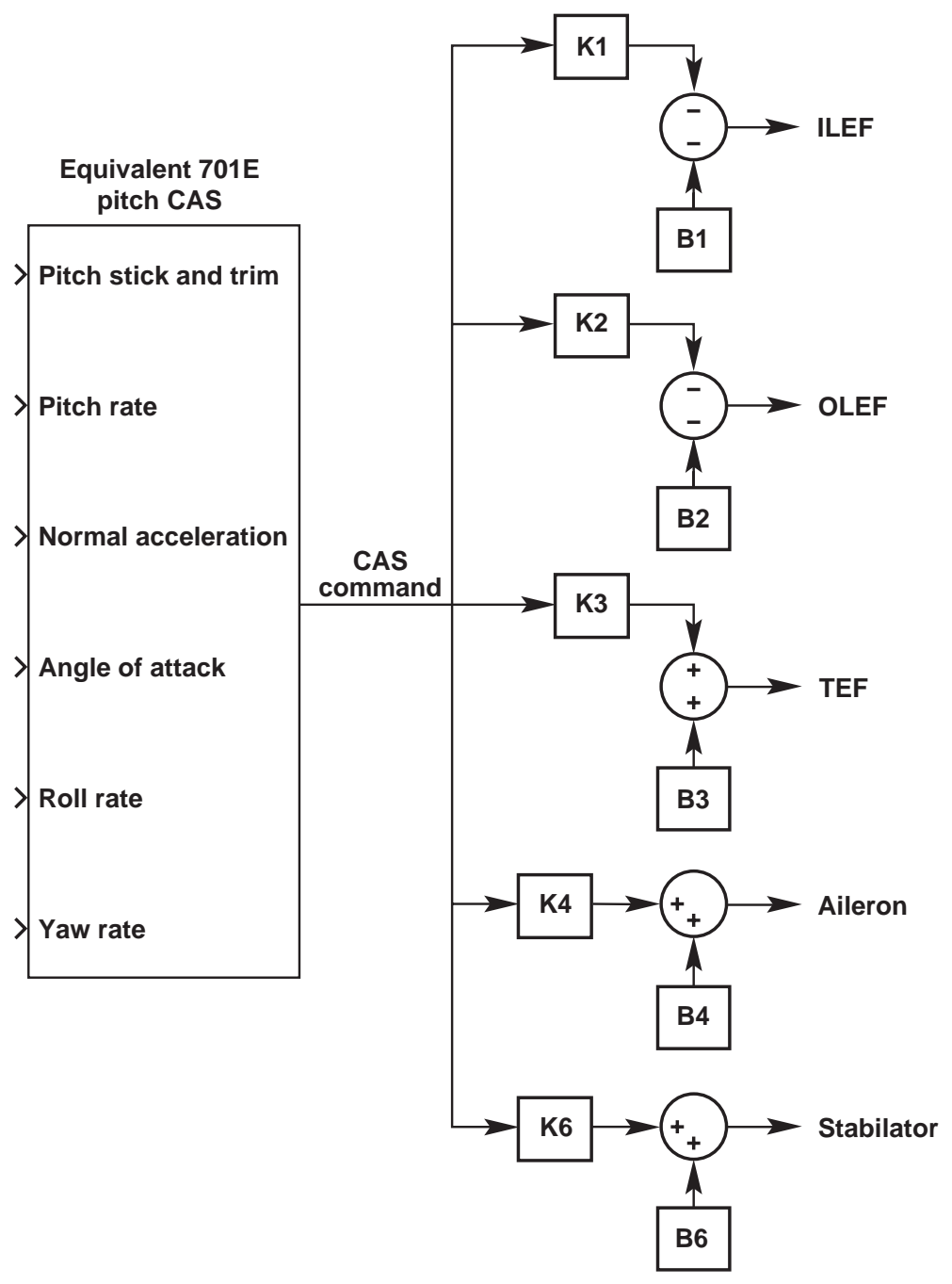

Figure 8. Simplified pitch-axis control laws in research flight control system. 

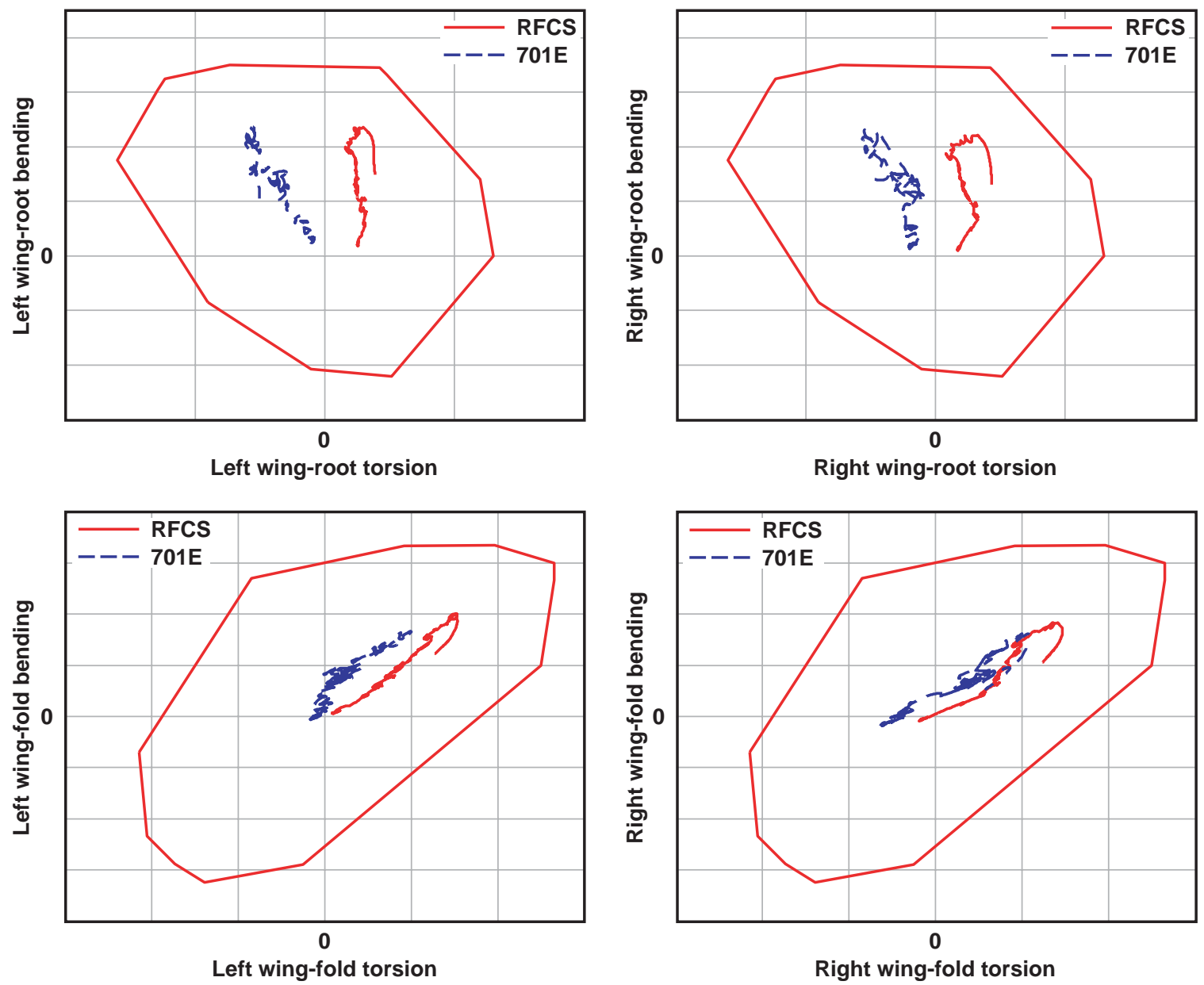

Figure 9. Bending and torsion moments during back-to-back 5-g windup turns performed at a subsonic region II test point.

The objective function of ISMD consists of the normalized radial distance of each load point from the origin rather than the distance from the X-Y axes of the torsional and bending moments. Thus, the objective function was computed from postflight data not only from the actual strain-gage measurements but from the predicted component loads as well. For the latter prediction, a loads model developed by DFRC was utilized. Figure 10 presents in the top graph, the objective function evaluated at discrete levels of the normal load factor along with the time histories of normal acceleration. Except at the 2-g level, the model predicts the objective function very well. As seen from the figure, however, the objective function evaluated from the RFCS data was actually higher than the 701E value at the 3-, 4-, and 5-g levels. Had the design followed the MLC strategy, the RFCS design should have had lower values than the $701 \mathrm{E}$ at all load levels. This apparent anomaly was further examined by comparing the RFCS and $701 \mathrm{E}$ symmetric control surface deflections on the wings in Fig.11. Observe that the RFCS control laws deflect the ailerons and the TEFs in the positive and negative directions, respectively. This deflection is exactly opposite of expectation from MLC, where the expected deflections would shift the load inboard to reduce the loads at elevated $g$ levels. 

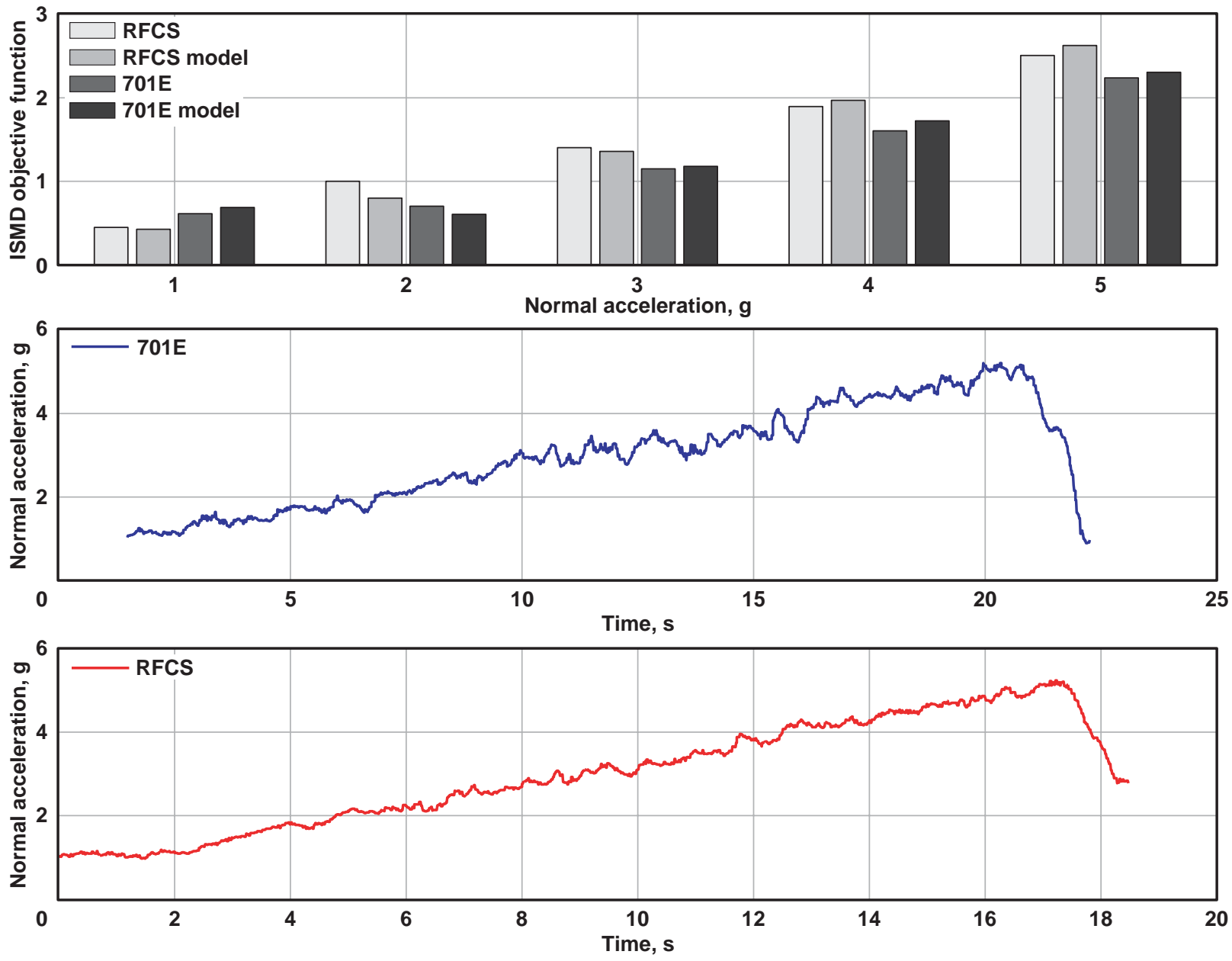

Figure 10. Integrated structure maneuver design objective function evaluated at 1, 2, 3, 4, and $5 \mathrm{~g}$. (Also shown are time histories of normal load factors during $5-g$ windup turns at a subsonic region II test point.) 

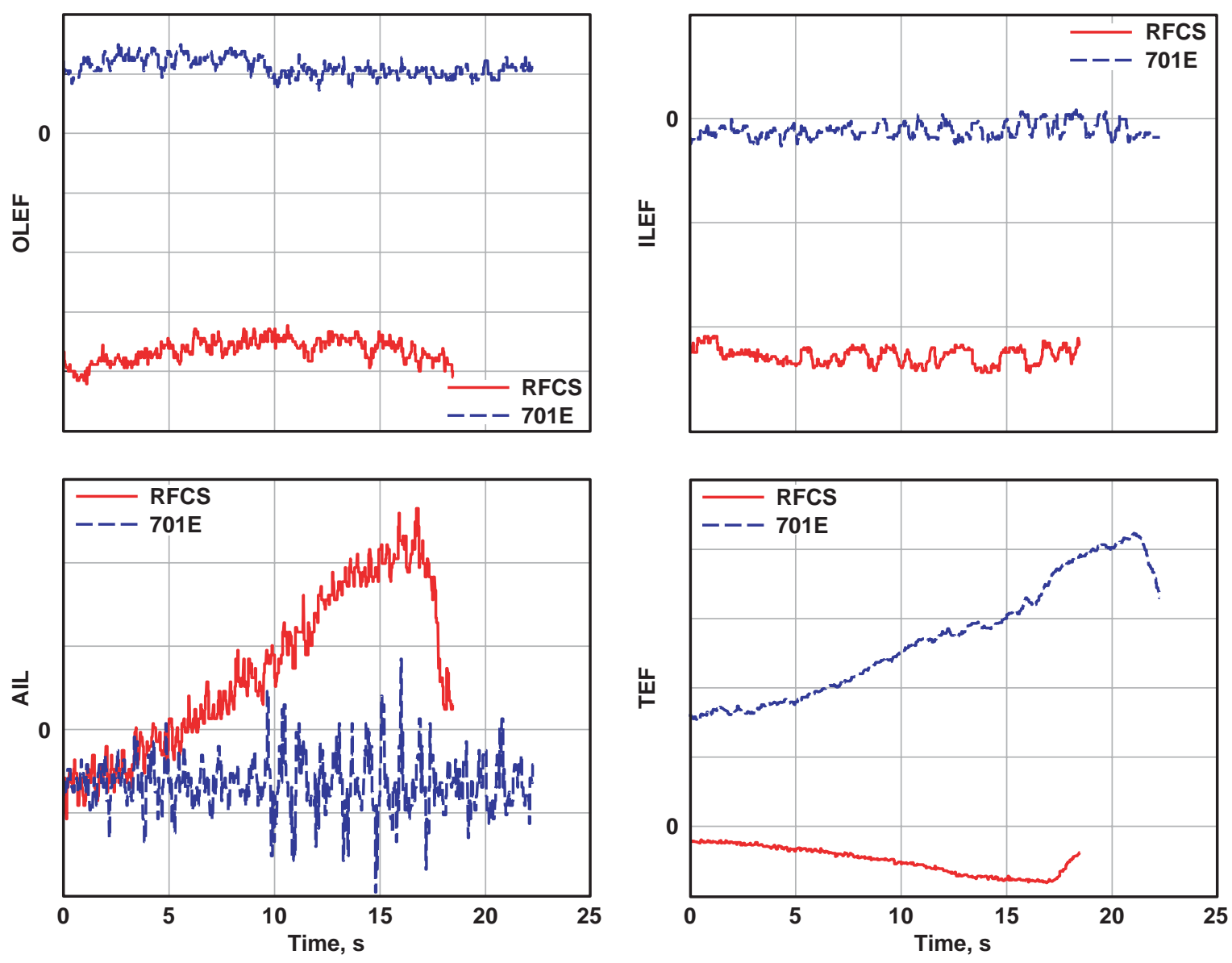

Figure 11. Wing control surface deflections during back-to-back 5-g windup turns performed at a subsonic region II test point.

\section{B. Lateral Axis}

In the lateral axis, the RFCS control laws use only wing leading- and trailing-edge control surfaces to provide all roll control; no use of differential stabilator was allowed. Figure 12 presents a simplified roll-axis block diagram. In the DFRC control laws, the roll-rate feedback gain was a small negative value, while in the Boeing control designs the roll-rate feedback gain was positive. The use of both negative and positive roll-rate feedback gains indicates that for the most part the control system was just acting as a mixer, computing the optimal surface deflections. 


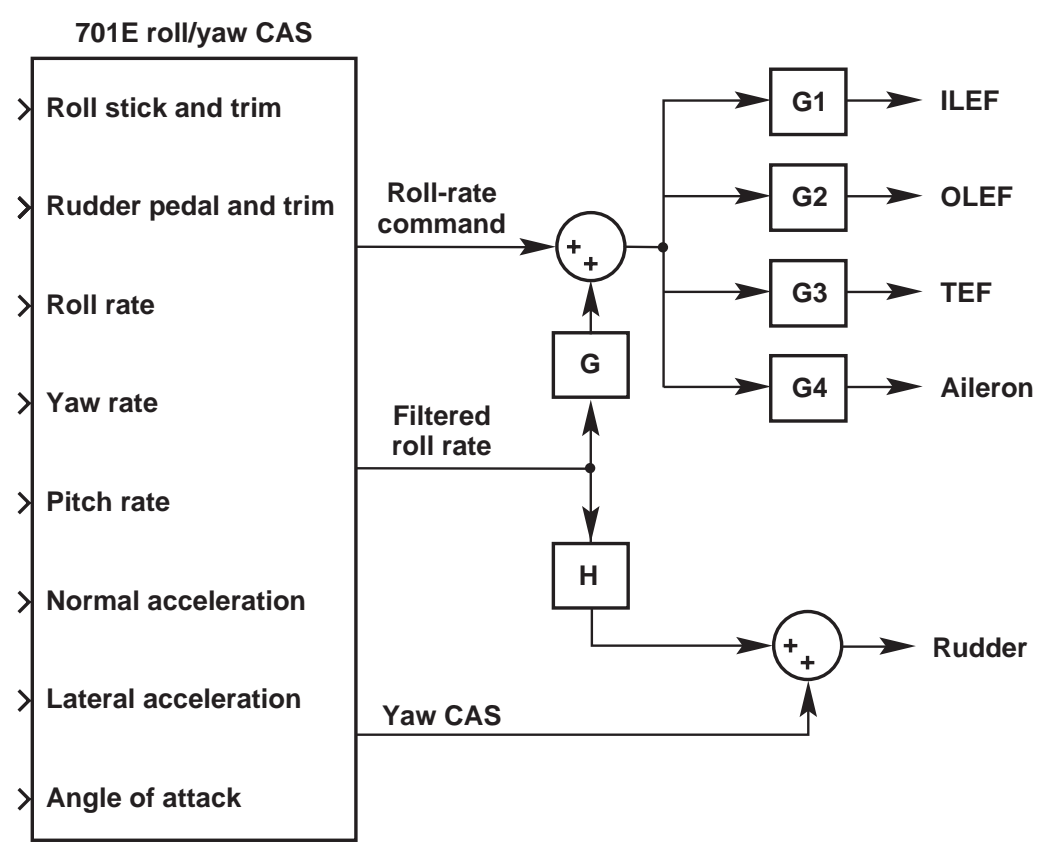

Figure 12. Simplified roll-axis control laws in research flight control system.

The DFRC designers conducted Monte Carlo testing of aerodynamic parameters and fuel loading as part of the preparation for flight test. If the Monte Carlo results indicated no violation of the safety-of-flight requirements, then the flight test proceeded until the flight data violated the safety-of-flight limits set on the roll coupling criteria or until the flight results looked significantly different from the simulation predictions. If the Monte Carlo indicated problems, the failed population was examined to discover thresholds that discriminated the failure cases from the rest of the population. Sometimes additional postflight analysis was required to determine if the flight data was part of the "good" or "bad" population.

Excursions in sideslip, lateral acceleration, and normal load factor were judged as the most significant lateral axis safety parameters. These parameters received more attention because the Naval Air Training and Operating Procedures Standardization (NATOPS) F/A-18 aircraft flight manual presents a bleak picture regarding roll departure for the F/A-18 airplane at high dynamic pressure. Excessive buildup of sideslip (predicted in the simulation) was one of the first signs of impending departure. Other signposts found in simulation testing for predicted departure were a rapid buildup in negative pitch rate and rudder control surface stall.

A variety of 1-g bank-to-bank and $360^{\circ}$ rolls were examined and three test points were picked for presentation in this section because they span the three regions of airplane roll response seen in the AAW program. The data presented in the following figures illustrate airplane responses that include a subsonic region I test point (dominated by trailing-edge control surfaces), a supersonic region II test point (equally effective trailing- and leading-edge control surfaces), and a subsonic region III test point (dominated by leading-edge control surfaces). We have normalized the data presented in the following series of figures and removed scales to comply with International Traffic in Arms Regulations.

Normalized roll performance data at the subsonic region I test point in Fig. 13 shows fairly linear roll rate to lateral stick response (the roll rate has been normalized with maximum roll rate recorded at this test point). The lateral-directional coupling parameters show adverse yaw (roll rate and sideslip have the same sign) and only small lateral accelerations. Normal acceleration excursions during the roll maneuvers also indicate coupling between the roll and pitch axes. At this subsonic region I test point, the minimum normal acceleration is less than 0.5 -g excursion from $1-g$, and the maximum normal acceleration is less than 1.5-g excursion from 1-g. Figure 14 shows a comparison of the flight-measured roll performance and the predicted performance using both the DFRC and Boeing aerodynamic models. These predictions were made using the DFRC nonlinear simulation initialized to the actual test point conditions and airplane weight. Flight-measured longitudinal and lateral stick inputs were used to drive the simulation. The figure shows flight-measured response is about halfway between the DFRC and Boeing aerodynamic model predictions in roll rate. The sideslip shows that the Boeing aerodynamic model predicted proverse yaw, whereas the DFRC aerodynamic model was almost neutral (starting proverse and becoming adverse 
as the roll maneuver progressed) and the flight data clearly shows adverse yaw. Figures $15 \mathrm{a}$ and $15 \mathrm{~b}$ show simulation comparison with flight data for an 80-percent lateral stick 4-g RPO. Both DFRC and Boeing aerodynamic models match the maneuver equally well. The data show that the additional $g$ of the RPO has caused the maneuver to be more adverse yaw in character.
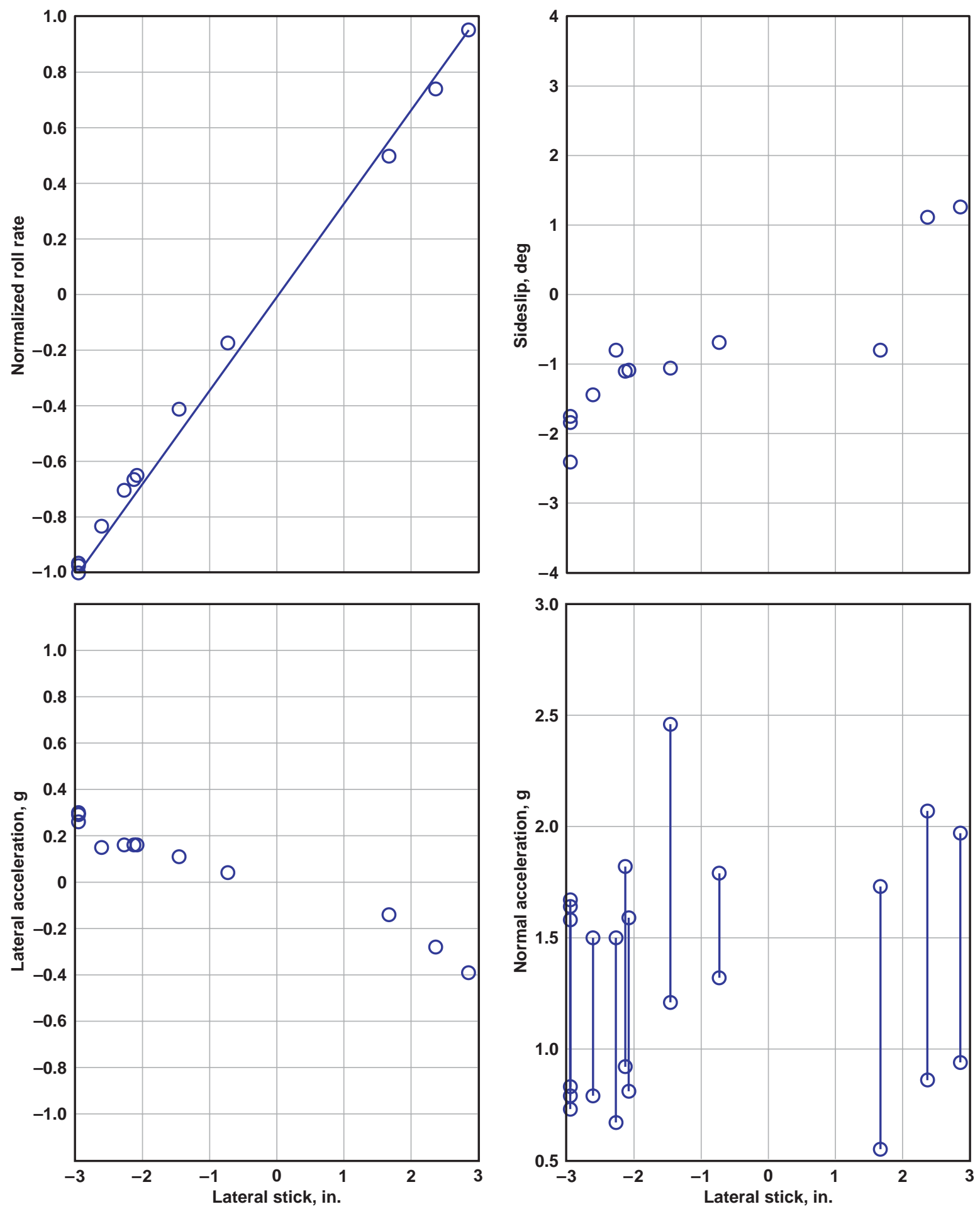

Figure 13. Normalized active aeroelastic wing roll performance data for a subsonic region I test point. 

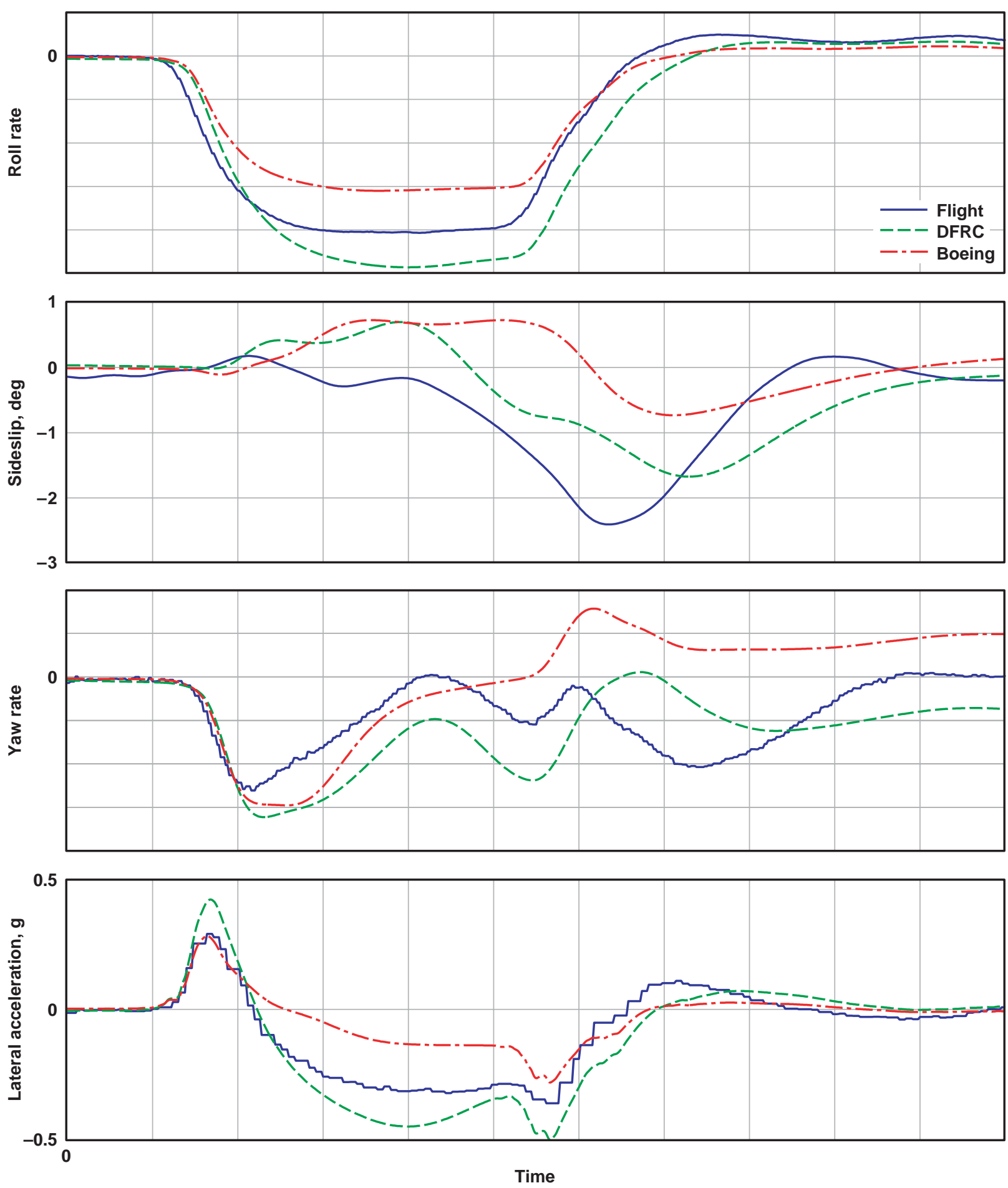

Figure 14. Comparison of active aeroelastic wing $1-g$ full lateral stick $360^{\circ}$ roll at a subsonic region I test point. 

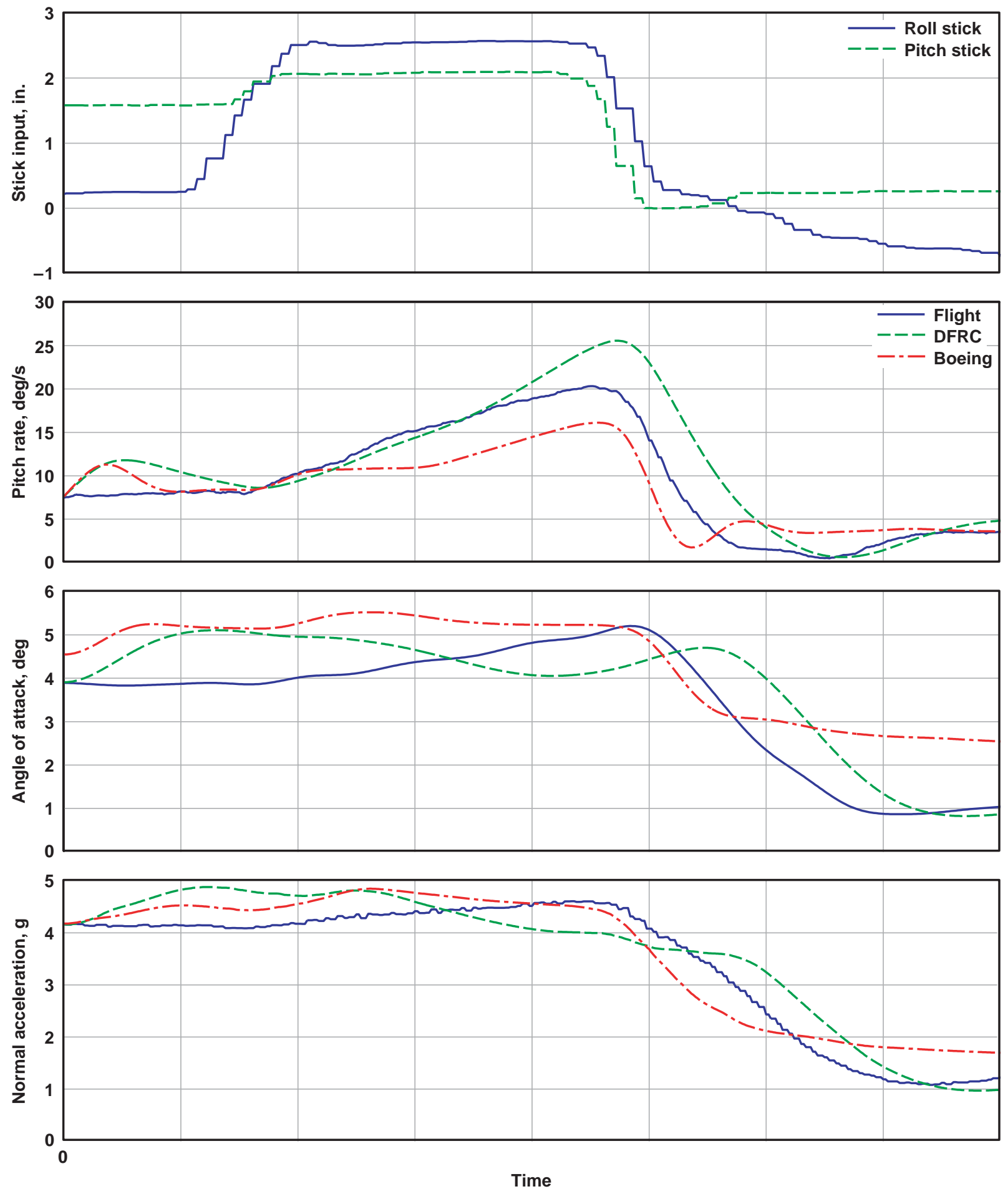

a) Pitch axis parameters.

Figure 15. Comparison of active aeroelastic wing 4-g 80-percent lateral stick rolling pullout at a subsonic region I test point. 

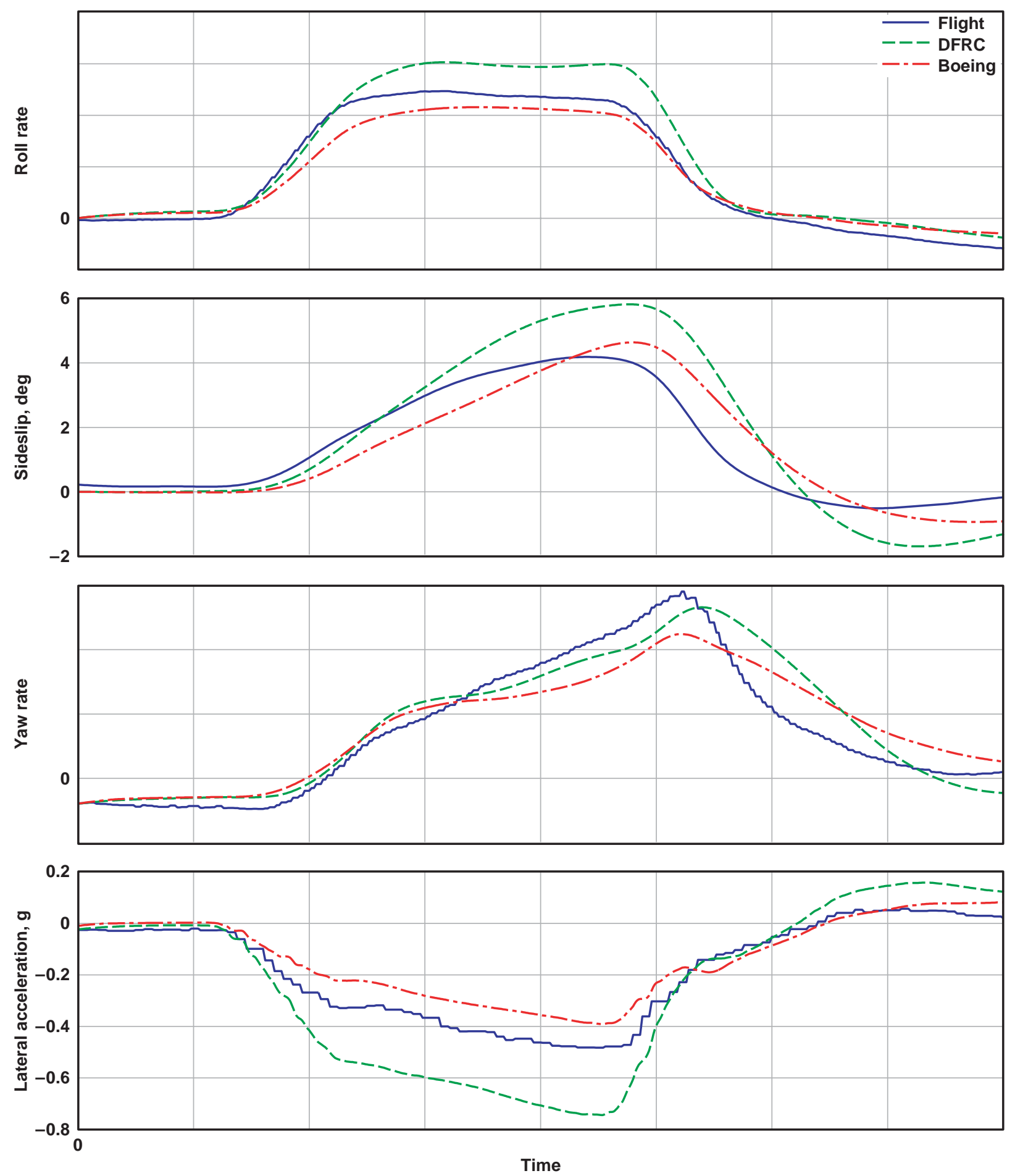

b) Roll and yaw axes parameters.

Figure 15. Concluded. 
Figures 16 and 17 show data for a supersonic region II test point. These data still show nearly linear response between lateral stick and roll rate. The coupling parameters exhibit the highest level of proverse yaw tendency seen during the Phase II flight tests. The level of sideslip at this test point was predicted to be slightly below the maximum allowed ( $4^{\circ}$ of proverse sideslip) for safety-of-flight. The major difference between the DFRC and Boeing aerodynamic models was the yawing moment due to TEF derivative. This issue had remained unresolved after the Phase I flight tests, but a 1970's report by Northrop engineers contains an explanation ${ }^{14}$ for the TEF yawing moment tendency. Northrop engineers had performed wind-tunnel tests that showed the TEF deflected the airflow into the vertical tails, which created yawing moments greater than the ability of the rudder to counteract. Figure 17 showed that for large lateral stick input, the Boeing aerodynamic model predicted almost no sideslip, while the DFRC aerodynamic model predicted $2.8^{\circ}$ of sideslip (proverse yaw). The flight data (limited to 75 -percent lateral stick at this condition) showed even worse than predicted proverse yaw tendency, confirming in large part the predictions made by the Northrop wind-tunnel test and Phase I results.

Figures 18 and 19 show the same set of data for the subsonic region III test point. At this test point, the normalized roll rate is also fairly linear with lateral stick. The coupling parameters at this test point are now showing proverse yaw tendencies (roll rate and sideslip having opposite sign), lateral acceleration is almost zero, and normal acceleration excursion are just a little larger than those seen at the subsonic region I test point. Figure 19 shows excellent agreement between the flight data and the DFRC predictions.

Performance criteria, such as time to bank and roll-mode time constant, were important metrics used to evaluate the AAW technology. The pilots were asked to perform only open-loop roll maneuvers to measure times to bank. They made no adverse comments regarding handling qualities or tendency to develop pilot-induced oscillations. Level 1 goals and level 2 time-to-bank requirements were stated for bank angles of $50^{\circ}, 90^{\circ}$, and $180^{\circ}$, for medium and high speeds, using the criteria in MIL Handbook 1797. Another time-to-bank requirement for ground attack was also examined. At the subsonic region I test point and supersonic region II test point, the AAW control designs met the level 1 goal for their respective speed range. At the subsonic region III test point, the roll performance was inadequate to meet the level 2 requirement.

Roll-mode time constant was estimated for several flight conditions. Matching the maximum performance roll-rate time response with a combined first order lag, or time constant, and time delay is the typical method used to extract low order system (LOS) parameters from high order system (HOS) measured data. Because of low data rate and unknown delays contained in the 1553 bus data used in this analysis, the time delay could not be estimated accurately. Although a value was used in the model, it does not represent an estimate of the time delay of overall system seen by the pilot. For this reason, we will not indicate the value of delay used in the time history matches presented in this section. The model was driven by an "effective" control surface input for open-loop and pilot lateral stick input for closed-loop matching. Given the size of the input and response in these maneuvers, this simple model matched the responses surprisingly well in many cases.

To gain some idea of the effects of FCS augmentation, the initial roll response of the unaugmented AAW aircraft was first evaluated. The response was clearly very fast in some cases, but quantifying the time constant was difficult when multiple control surfaces were active. Tests of DFRC designs for another of the subsonic region III test points, however, used only the OLEF and at another of the supersonic region II test points used only the leading-edge devices, thereby allowing estimation of the time constant of the basic aircraft. The time constants were around 0.1 and 0.25 seconds, respectively, which turned out to be close to the augmented values for these conditions. Figure 20 illustrates the open-loop, or unaugmented, match of the LOS and HOS data for this supersonic region II test point. 

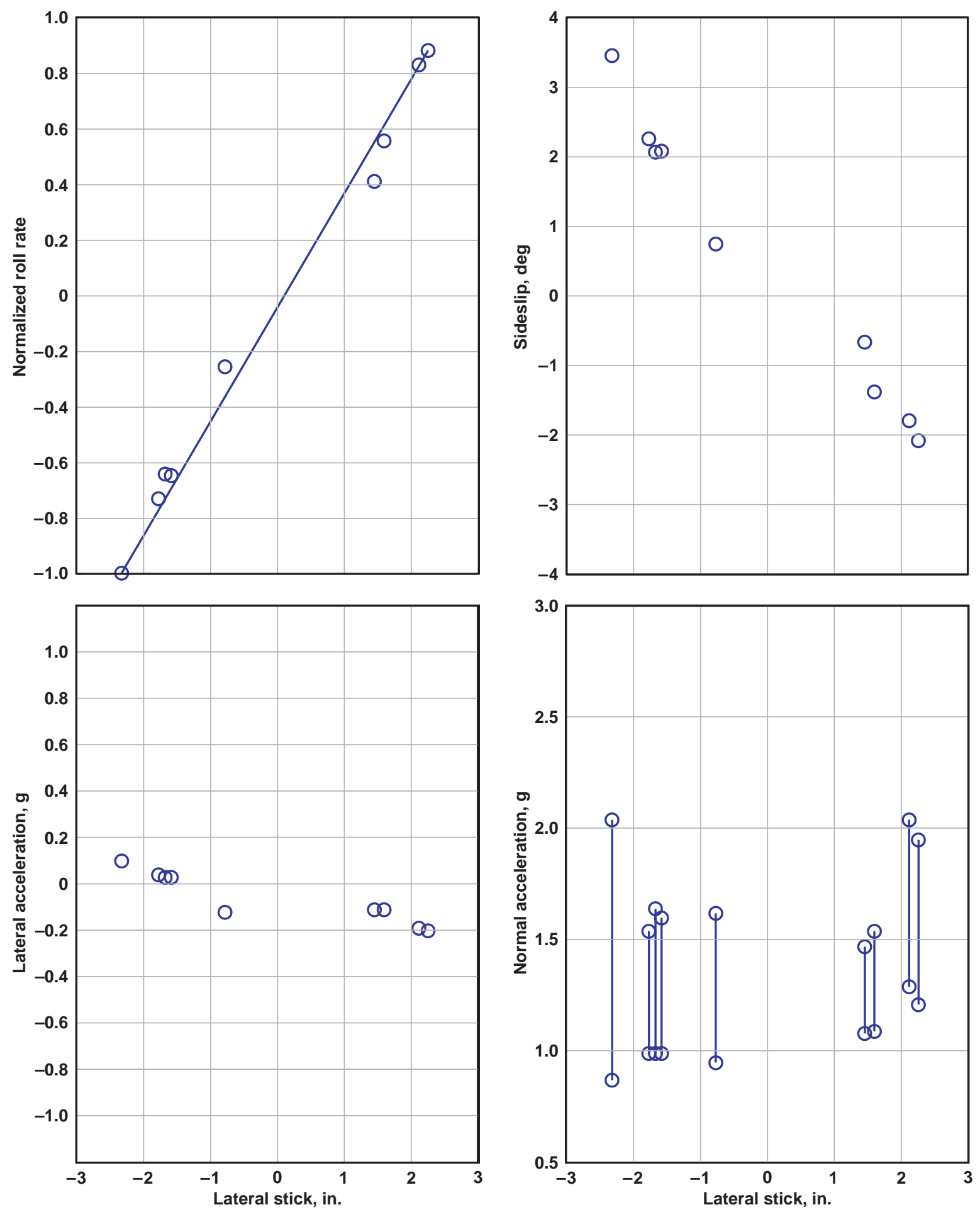

Figure 16. Normalized active aeroelastic wing roll performance data for a supersonic region II test point. 

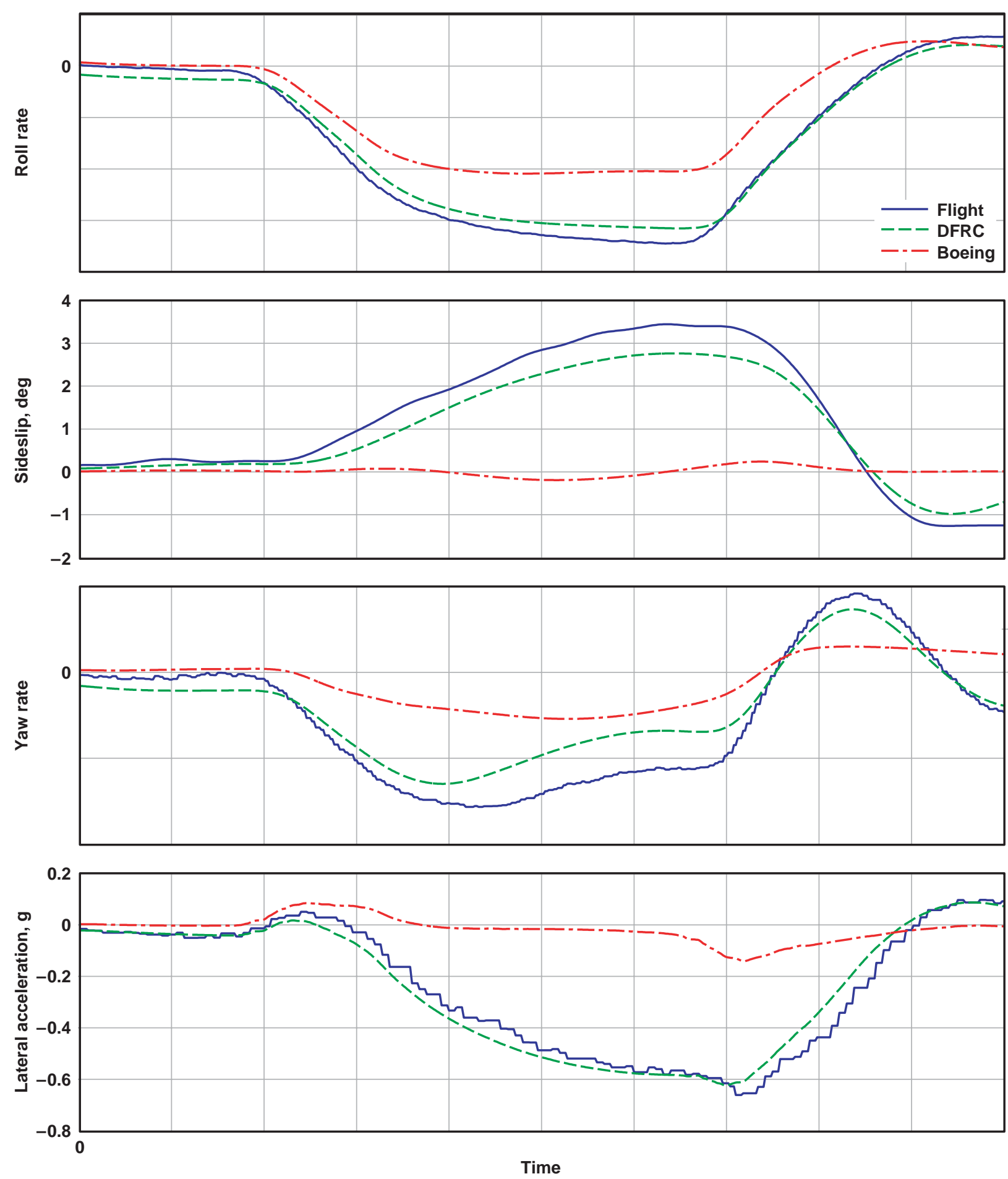

Figure 17. Comparison of active aeroelastic wing 1-g 75-percent lateral stick $360^{\circ}$ roll at a supersonic region II test point. 

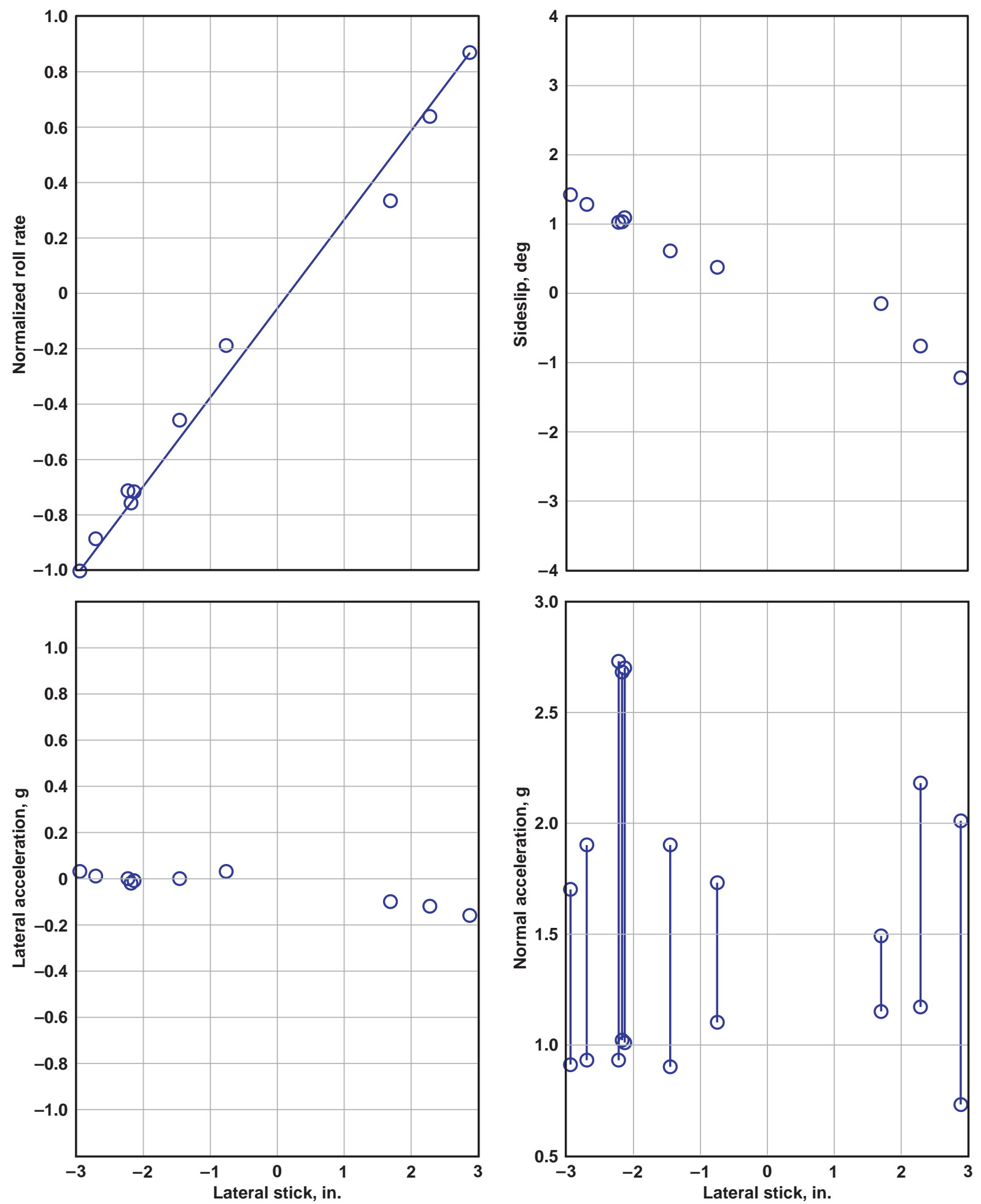

Figure 18. Normalized active aeroelastic wing roll performance data for a subsonic region III test point. 

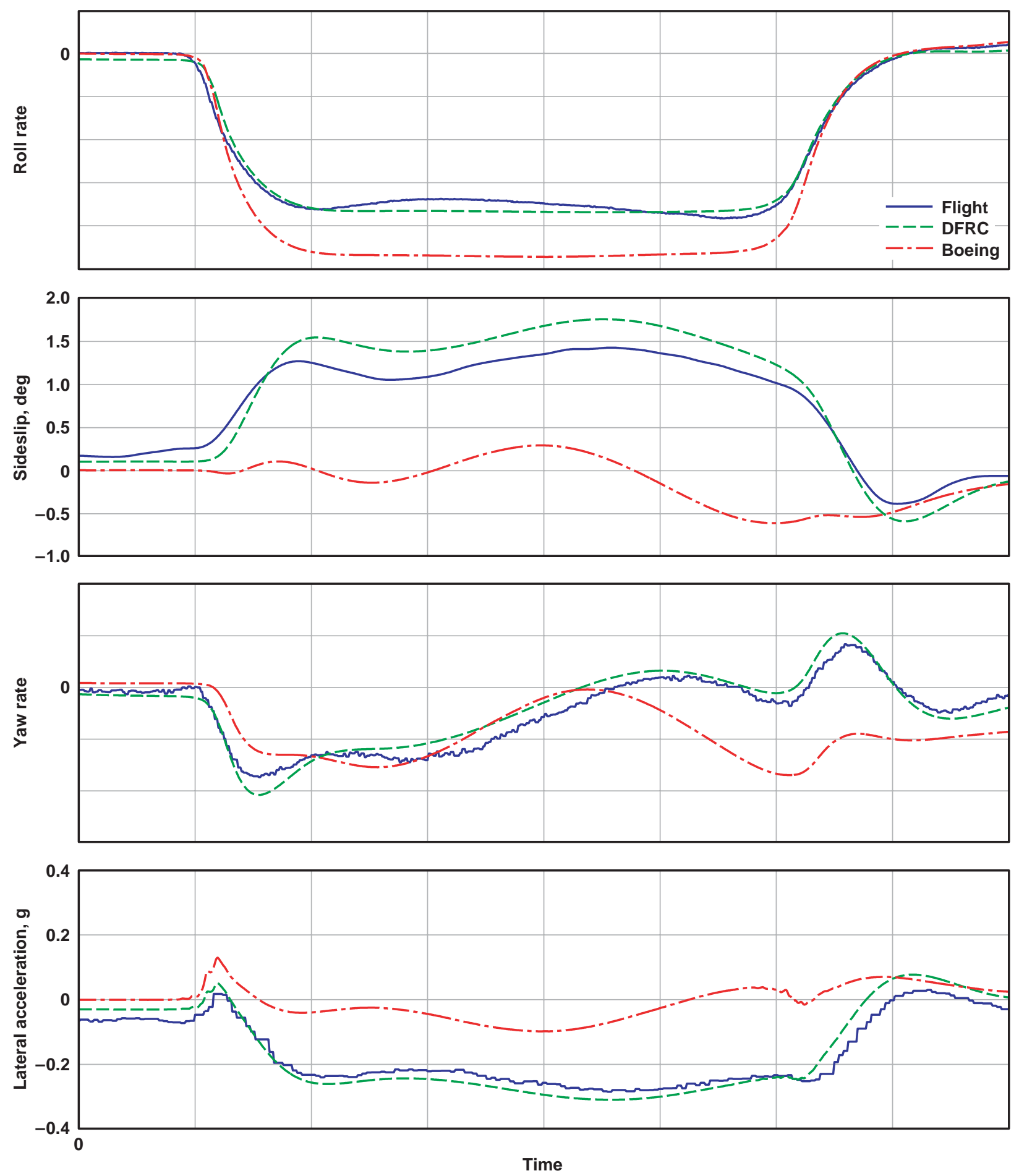

Figure 19. Comparison of active aeroelastic wing 1-g full lateral stick $360^{\circ}$ roll at a subsonic region III test point. 

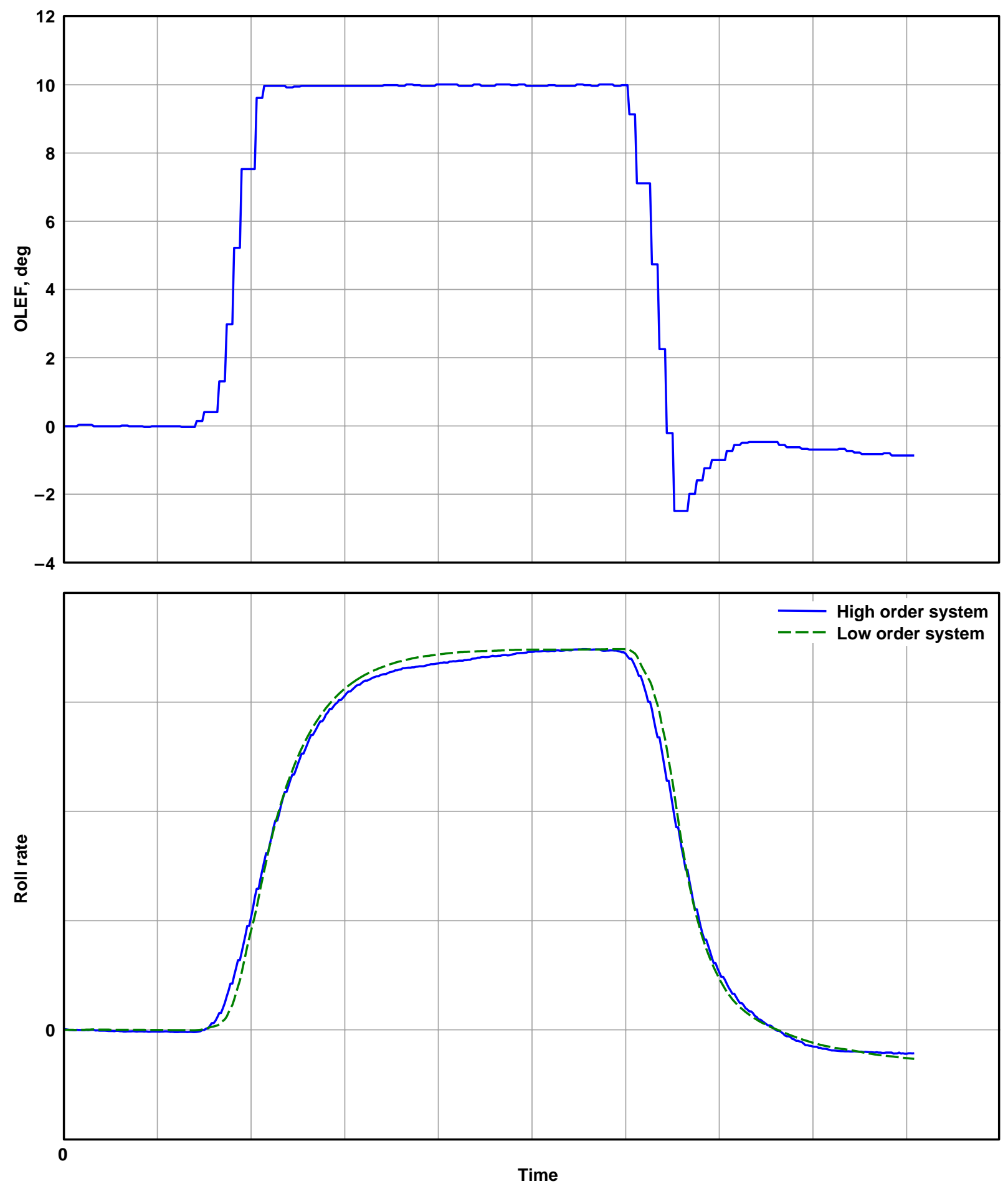

Figure 20. Roll-rate response to outboard leading-edge flap at another supersonic region II test point. 
Figure 21 illustrates that for this test point, augmentation decreases the time constant only slightly (to a value of 0.21 seconds). Augmentation also caused the response to be more first-order in appearance as evidenced by a slightly better match between the LOS and flight data.
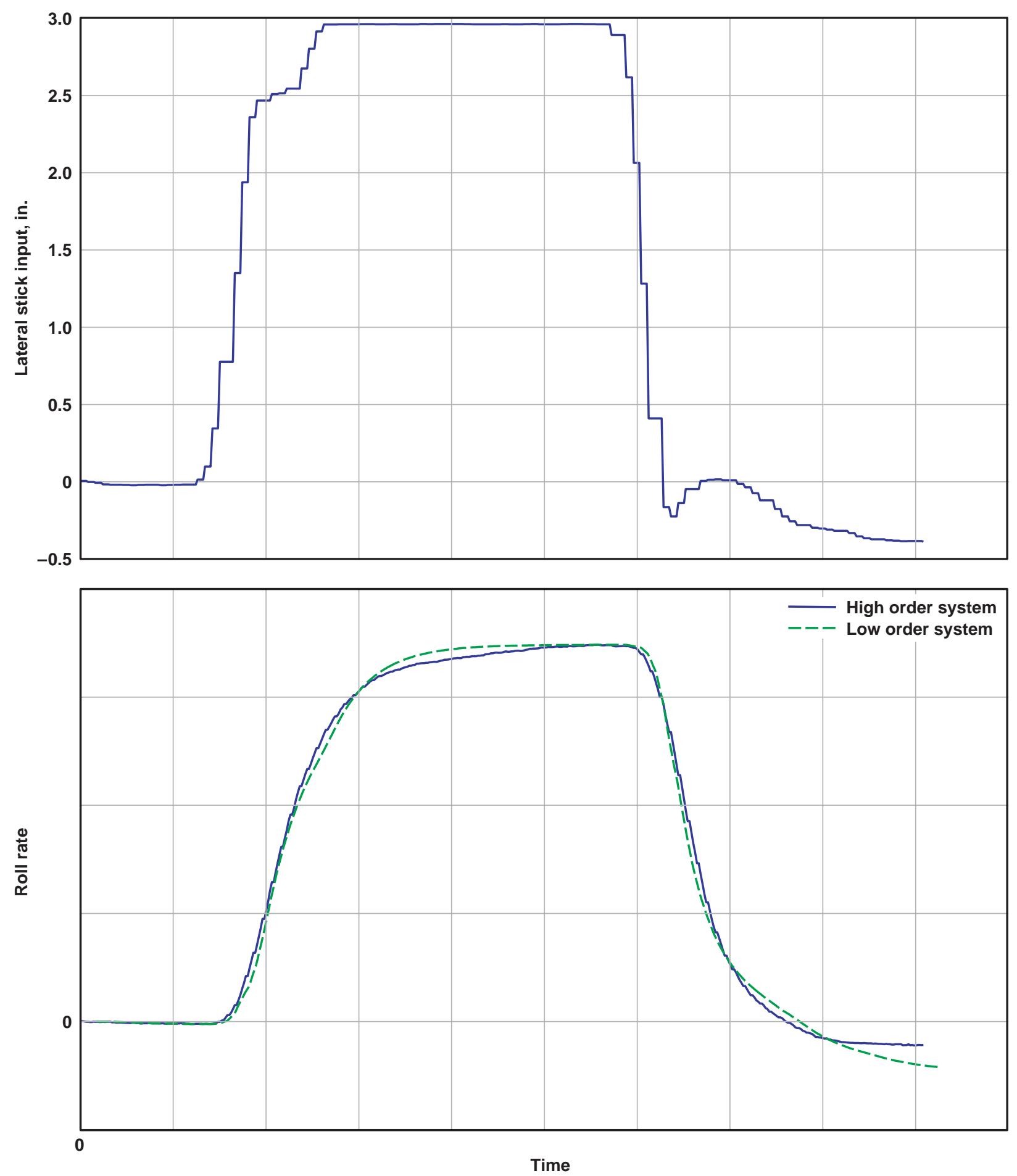

Figure 21. Roll-rate response to pilot lateral input at another supersonic region II test point. 
The criteria for roll-mode time constant were not to exceed 1 second for level 1 and 1.4 seconds for level 2. The time constants were very short for the subsonic region I test point and subsonic region III test point, with values of 0.18 and 0.1 seconds respectively, which were quicker than the 0.3 seconds guideline. The supersonic region II test point had a time constant of 0.6 seconds, which met the level 1 requirement. The portion of the roll-mode time constant guideline that dealt with quick time constants was developed for the AAW program because of a concern with roll-ratchet pilot-induced oscillation. That same project requirements document, however, allowed quick roll-mode time constants if they were no worse than that of the basic 701E control laws. These quick AAW roll-mode time constants meet the looser criterion.

\section{Concluding Remarks}

After nearly ten years, from program kickoff to last flight, Active Aeroelastic Wing (AAW) technology was finally flight-tested on a full-scale airplane and most program objectives were met. Flight tests of the AAW airplane were accomplished in two phases; Phase I concentrated on aerodynamic and loads model development whereas Phase II contained the entire flight test of the new closed-loop control laws. Both phases of the program were conducted without incident, using buildup procedures that allowed $1-g, 360^{\circ}$ rolls, and rolling pullout maneuvers to be tested up to the structural and hinge-moment limits of the airplane. Although the airplane preparations for Phase II flight test took a long time, the objectives were accomplished in a short time (approximately 3.5 calendar months) and only 35 total flights.

1) Phase I flight test using the onboard excitation system successfully provided data for aerodynamic and loads model development. Hindsight showed that some of the doublet maneuvers were too small and significant extrapolation of the wing leading-edge flap control power was required.

2) Phase I results showed no tendency for the aileron to fully reverse. During AAW testing, the aileron roll control moments approached zero and stayed there, but did not exhibit reversal. Examination of control position transducers placed on the control surfaces indicated that substantial control surface flexibility might have contributed to elastic relief of the hinge moment that these "tabs" were applying to the wing.

3) The research flight control system worked well in both Phase I and Phase II. The AAW research program demonstrated the first use of such a system on an F/A-18 airplane in a safety-of-flight critical envelope.

4) The AAW airplane was unable to accomplish any flight tests at the highest dynamic pressures. Both Mach 1.3 at an altitude of $15,000 \mathrm{ft}$ and Mach 1.2 at an altitude of 10,000 $\mathrm{ft}$ proved to be outside of the performance envelope of the airplane. Modifications to the wing for the flight deflection measurement system and externally mounted wiring may have contributed to this problem.

5) The IADS ${ }^{\circledast}$ air data display provided insight into the uncalibrated impact and static pressures that the flight control system was using to set its gains. This real-time display allowed the test conductor to guide the pilot to the proper conditions and allowed him to make valuable terminate calls to ensure that the pilot would not have aileron hinge-moment overloads.

6) The aileron hinge moment was a design driver for the flight control system design.

7) Comparison of the Phase II flight data and predicted airplane response showed excellent agreement at supersonic conditions. The subsonic agreement was fair, and larger differences were noted between the predictions and flight test data.

8) The newly designed flight control laws failed to show load reduction at a subsonic region II test point for elevated $g$ levels when compared with the production flight control system. Examination of the responses showed that the trailing-edge control surfaces were driven in a manner inconsistent with maneuver load control strategies.

\section{References}

${ }^{1}$ Miller, Gerald D., “Active Flexible Wing (AFW) Technology,” AFWAL-TR-87-3096, February 1988, available from Flight Dynamics Laboratory, Air Force Wright Aeronautical Laboratories, Wright-Patterson AFB, Ohio.

${ }^{2}$ Noll, Thomas E., Perry, Boyd, III, Tiffany, Sherwood H., Cole, Stanley R., Buttrill, Carey S., Adams, William M, Jr., Houck, Jacob A., Srinathkumar, S., Mukhopadhyay, Vivek, Pototzky, Anthony S., Heeg, Jennifer, McGraw, Sandra M., Miller, Gerald, Ryan, Rosemary, Brosnan, Michael, Haverty, James, and Klepl, Martin, Aeroservoelastic Wind-Tunnel Investigations Using the Active Flexible Wing Model - Status and Recent Accomplishments, NASA TM-101570, 1989.

${ }^{3}$ Perry, Boyd, III, Cole, Stanley R., and Miller, Gerald D., "Summary of an Active Flexible Wing Program," Journal of Aircraft, Vol. 32, No. 1, January-February 1995, pp. 10-15.

${ }^{4}$ Pendleton, Edmund, Lee, Mark, and Wasserman, Lee, "Application of Active Flexible Wing Technology to the Agile Falcon," Journal of Aircraft, Vol. 29, No. 3, May-June 1992, pp. 444-451. 
${ }^{5}$ Pendleton, Ed, Griffin, Kenneth E., Kehoe, Michael W., and Perry, Boyd, "A flight research program for active aeroelastic wing technology," AIAA/ASME/ASCE/AHS/ASC Structures, Structural Dynamics and Materials Conference and Exhibit, 37th, Salt Lake City, UT, AIAA -96-1574, April 15-17, 1996, pp. 2263-2273.

${ }^{6}$ Regenie, Victoria, Gatlin, Donald, Kempel, Robert, and Matheny, Neil, "The F-18 High Alpha Research Vehicle: A High-Angle-of-Attack Testbed Aircraft," 6th AIAA Biennial Flight Test Conference, Hilton Head Island, SC, AIAA-92-4121, August 24-26, 1992.

${ }^{7}$ Carter, John, F., Production Support Flight Control Computers: Research Capability for F/A-18 Aircraft at Dryden Flight Research Center, NASA/TM-97-206233, 1997.

${ }^{8}$ Dibley, Ryan P., Allen, Michael J., and Clarke, Robert, "Development and Testing of Control Laws for the Active Aeroelastic Wing Program," AIAA Atmospheric Flight Mechanics Conference and Exhibit, San Francisco, CA, AIAA-2005-6314 submitted for publication, August 15-18, 2005.

${ }^{9}$ Lokos, William A., Olney, Candida, D., Chen, Tony, Crawford, Natalie D., Stauf, Rick, and Reichenbach, Eric Y., "Strain-Gage Load Calibration Testing of the Active Aeroelastic Wing F/A-18 Airplane," AIAA Dynamic Measurement Technology and Ground Testing Conference, St. Louis, MO, AIAA-2002-2926, 2002.

${ }^{10}$ Cumming, Stephen, B. and Diebler, Corey G., "Active Aeroelastic Wing Aeromodel Development and Validation for a Modified F-18A," AIAA Atmospheric Flight Mechanics Conference and Exhibit, San Francisco, CA, AIAA-2005-6312 submitted for publication, August 15-18, 2005.

${ }^{11}$ Allen, Michael J., Lizotte, Andrew, Dibley, Ryan P., and Clarke, Robert, "Loads Model Development and Test for the F/A-18 Active Aeroelastic Wing Airplane," AIAA Atmospheric Flight Mechanics Conference and Exhibit, San Francisco, CA, AIAA-2005-6313 submitted for publication, August 15-18, 2005.

${ }^{12}$ Pendleton, Edmund W., Bessette, Denis, Field, Peter B., Miller, Gerald D., and Griffin, Kenneth E., "Active Aeroelastic Wing Flight Research Program: Technical Program and Model Analytical Development," Journal of Aircraft, Vol. 37, No. 4, AIAA Paper 96-1574, July-August 2000, pp. 554-561.

${ }^{13}$ Miller, G. D., "An Active Flexible Wing Multi-Disciplinary Design Optimization Method,” AIAA/USAF/NASA/ISSMO Symposium on Multidisciplinary Analysis and Optimization, 5th, AIAA, Washington, May 1994, pp. 1388-1394.

${ }^{14}$ Moynes, John F. and Nelson, Wallace E., Jr., "Flaperon Control - the Versatile Surface for Fighter Aircraft," Aerodynamic Characteristics of Controls, CP262, AGARD, Pozzuoli, Italy, May 14-17, 1979, pp. 9.1-9.16. 